\title{
Skeletal light-scattering accelerates bleaching response in reef-building corals
}

Timothy D. Swain ${ }^{1,2}$, Emily DuBois ${ }^{1,2}$, Andrew Gomes ${ }^{3}$, Valentina P. Stoyneva ${ }^{3}$, Andrew J. Radosevich ${ }^{3}$, Jillian Henss ${ }^{1,2}$, Michelle E. Wagner ${ }^{1,2}$, Justin Derbas ${ }^{3}$, Hannah W. Grooms ${ }^{1}$, Elizabeth M. Velazquez', Joshua Traub' ${ }^{1}$, Brian J. Kennedy ${ }^{1}$, Arabela A. Grigorescu' ${ }^{4}$, Mark W. Westneat ${ }^{2}$, Kevin Sanborn $^{5}$, Shoshana Levine ${ }^{5}$, Mark Schick ${ }^{5}$, George Parsons ${ }^{5}$, Brendan C. Biggs ${ }^{6}$, Jeremy D. Rogers ${ }^{3}$, Vadim Backman ${ }^{3}$ and Luisa A. Marcelino ${ }^{1,2^{*}}$

\begin{abstract}
Background: At the forefront of ecosystems adversely affected by climate change, coral reefs are sensitive to anomalously high temperatures which disassociate (bleaching) photosynthetic symbionts (Symbiodinium) from coral hosts and cause increasingly frequent and severe mass mortality events. Susceptibility to bleaching and mortality is variable among corals, and is determined by unknown proportions of environmental history and the synergy of Symbiodinium- and coral-specific properties. Symbiodinium live within host tissues overlaying the coral skeleton, which increases light availability through multiple light-scattering, forming one of the most efficient biological collectors of solar radiation. Light-transport in the upper $200 \mu \mathrm{m}$ layer of corals skeletons (measured as 'microscopic' reduced-scattering coefficient, $\left.\mu_{S, m}^{\prime}\right)$, has been identified as a determinant of excess light increase during bleaching and is therefore a potential determinant of the differential rate and severity of bleaching response among coral species.

Results: Here we experimentally demonstrate (in ten coral species) that, under thermal stress alone or combined thermal and light stress, low- $\mu_{S, m}^{\prime}$ corals bleach at higher rate and severity than high- $\mu_{S, m}^{\prime}$ corals and the Symbiodinium associated with low- $\mu_{S, m}^{\prime}$ corals experience twice the decrease in photochemical efficiency. We further modelled the light absorbed by Symbiodinium due to skeletal-scattering and show that the estimated skeleton-dependent light absorbed by Symbiodinium (per unit of photosynthetic pigment) and the temporal rate of increase in absorbed light during bleaching are several fold higher in low- $\mu_{S, m}^{\prime}$ corals.

Conclusions: While symbionts associated with low- $\mu_{S, m}^{\prime}$ corals receive less total light from the skeleton, they experience a higher rate of light increase once bleaching is initiated and absorbing bodies are lost; further precipitating the bleaching response. Because microscopic skeletal light-scattering is a robust predictor of light-dependent bleaching among the corals assessed here, this work establishes $\mu_{S, m}^{\prime}$ as one of the key determinants of differential bleaching response.
\end{abstract}

Keywords: Global climate change, Optical scattering, Coral bleaching, Photosynthesis, Symbiosis

\section{Background}

At the forefront of ecosystems adversely affected by climate change, coral reefs are sensitive to anomalously high temperatures which disassociate (bleaching)

\footnotetext{
*Correspondence: I-marcelino@northwestern.edu

2 Department of Zoology, Field Museum of Natural History, 1400 South

Lake Shore Drive, Chicago, IL 60605, USA

Full list of author information is available at the end of the article
}

photosynthetic symbionts (Symbiodinium) from coral hosts and cause increasingly frequent and severe mass mortality events [1-4]. Susceptibility to bleaching and mortality is variable among corals $[2,5-8]$, and is partially determined (at unknown proportions) by a combination of environmental history $[9,10]$ and the interaction of Symbiodinium- [2, 11-14] and coral-specific $[8,15-19]$ properties (reviewed in [20]). 
As photosynthetic performance of in hospite Symbiodinium is often impaired during thermally-induced bleaching (e.g., [21-23]), the interaction of temperature and irradiance exacerbate the bleaching response (reviewed in $[4,20,24,25])$. Corals under thermal stress experience greater damage to the Symbiodinium photosynthetic apparatus (chronic photoinhibition of PSII) and elevated bleaching response when exposed to supraoptimal solar irradiances, indicating that temperature reduces the light intensity threshold for photoinhibition $[4,21,25,26]$.

Symbiodinium live within host tissues overlaying the coral skeleton, which can significantly increase light availability to symbionts through multiple scattering [15-18, 27], and together with within-tissue scatter and dynamic light redistribution (due to tissue contraction and scattering or absorption by host fluorescent pigments) [19, 28] form one of the most efficient biological collectors of solar radiation $[15,29]$. This increase in light-availability is dependent on density and absorption properties of symbiont and host pigments and on diffuse reflectance of light from coral skeleton $\left(R_{S}\right)$ and tissue, which is mainly reliant on light scattering and absorption in the skeleton and tissue as well as overall coral morphology [15, 17-19, 27-33]. Scattering in skeletons (characterized by the reduced scattering coefficient, bulk- $\mu_{S}^{\prime}$ or $\mu_{S}^{\prime}$ : inverse of the distance a photon travels before randomization) is mainly due to light interaction with skeletal microstructures throughout the entire skeleton (from 50 to $200 \mathrm{~nm}$ $\mathrm{CaCO}_{3}$ nanograins to $1-5 \mu \mathrm{m}$ fiber bundles; [34, 35]) and larger length-scale structures (hundreds of micron size septa to millimeter size corallites; [15, 27, 36]). Furthermore, scattering in the superficial layer of coral skeletons (measured as microscopic- $\mu_{S}^{\prime}$ or $\mu_{S, m}^{\prime}$ : the inverse distance a short-path length photon travels before randomization $[18,37])$ governs light-transport at sub-diffusion path lengths $(\sim 100 \mu \mathrm{m})$ and is affected by skeletal microstructures, but not larger length-scale structures [18]. Thus $\mu_{S, m}^{\prime}$ can be described as $\mu_{S}^{\prime}$ of the skeletal material itself, within the top $\sim 100 \mu \mathrm{m}$ of the skeleton without voids [18]. Although $R_{S}$ includes the effect of $\mu_{S, m}^{\prime}$, it is primarily determined by $\mu_{S}^{\prime}$, absorption, and overall coral morphology [15, 18, 27, 29-31].

Greater total skeletal reflectance, associated with higher $\mu_{S}^{\prime}$, has been demonstrated to increase lightabsorption by at least six times for symbionts in hospite and in simulations compared to those in vitro $[15,17]$. By estimating absorption efficiency in differentially bleached corals and skeletal models (e.g., polished-laminae), it has been shown that skeletal light amplification (excess light available to the symbiont) is inversely related to symbiont concentration, leading to the prediction that skeletal $\mu_{S}^{\prime}$ could exacerbate the feedback of increasing photodamage for remaining Symbiodinium as symbiont densities diminish during bleaching (positive feedbackloop hypothesis) $[15,17,29]$. However, the rate of excess light increase as symbiont densities decrease has been demonstrated in models to be highly variable among corals, with high rates of excess light increase inversely correlated with skeletal $\mu_{S, m}^{\prime}$ [18]. Low skeletal $\mu_{S, m}^{\prime}$ values were significantly correlated with heightened bleaching susceptibility in a retrospective analysis of global bleaching events for 94 coral taxa, leading to the prediction that $\mu_{S, m}^{\prime}$ (as the optical property responsible for the rate of feedback) is a potential determinant of the severity of bleaching response for this mechanism [18]. In this previous study, neither $\mu_{S}^{\prime}$ nor $R_{S}$ were correlated with historical bleaching response [18].

To consolidate previous findings and provide predictions about the bleaching process that can be experimentally assessed, we propose the optical feedback hypothesis based on the effect of short-path light-transport. Although skeletal contribution to the endosymbiotic light microenvironment is normally small [38], skeletal optical properties become increasingly important as symbionts are lost and the skeleton becomes more exposed to light [18]. As densities of light absorbers (Symbiodinium cells and/or their photosynthetic pigments) decrease during the bleaching response, the coral skeleton becomes progressively exposed to downwelling light and dynamically becomes an increasingly significant source of excess light to remaining symbionts, compounding stress on Symbiodinium and provoking a more rapid and severe bleaching response. This feedback loop may proceed at differential rates that are determined by the rate at which the skeleton increases excess light to symbionts, as Symbiodinium and pigment concentrations decline [18]. As the optical property that is predictive of the rate of excess light increase as a function of pigment density, $\mu_{S, m}^{\prime}$ affects the rate of feedback and may therefore be a determinate of bleaching severity [18]. We therefore predict that, depending on skeletal $\mu_{S, m}^{\prime}$, corals that are bleaching should be differentially exposed to stress, and low- $\mu_{S, m}^{\prime}$ corals should experience: (1) increased rates and severities of bleaching response, with Symbiodinium remaining in hospite showing increased rates and severities of light stress, and (2) increased skeleton-dependent light absorption by remaining Symbiodinium. Furthermore, (3) skeletal $\mu_{S, m}^{\prime}$ should be a good predictor of the light-dependent bleaching effect but a poor predictor of temperature-dependent bleaching. These predictions of the optical feedback hypothesis have not been experimentally demonstrated among corals with diverse skeletal optical properties $\left(\mu_{S, m}^{\prime}\right.$ and $\left.R s\right)$; which due to the dynamic nature of feedback, must be assessed as corals undergo bleaching. 
Here we describe a heat- and light-stress experiment that demonstrates the effect of skeletal $\mu_{S, m}^{\prime}$ on bleaching response using ten coral species selected for diversity of bleaching susceptibilities, skeletal optical properties, and Symbiodinium thermotolerances. By following the dynamics of holobiont response to stress directly, and developing a novel empirical model of skeleton-dependent light-absorption for in hospite Symbiodinium, we assessed the general predictions for coral bleaching under the optical feedback mechanism detailed above. The combined experimental and empirical modeling substantiates the predictions of the optical feedback hypothesis by establishing a connection between the dynamics of skeletal light amplification, bleaching response, in hospite Symbiodinium light absorption, and photophysiology among a diverse group of corals.

\section{Results}

\section{Skeletal and holobiont optical characteristics}

Microscopic scattering, $\mu_{S, m}^{\prime}$, varied between 1.53 and $5.8 \mathrm{~mm}^{-1}$ (Table 1), with low- $\mu_{S, m}^{\prime}$ corals (defined as below the mean of the ten species assessed: Merulina sp., Pocillopora damicornis, Seriatopora hystrix, and Stylophora pistillata) averaging $2.01 \pm 0.27 \mathrm{~mm}^{-1}$ (mean \pm std error) and high- $\mu_{S, m}^{\prime}$ corals (Diploria labyrinthiformis, Goniopora sp., Favia favus, Montipora foliosa, and Montipora digitata) averaging $4.58 \pm 0.34 \mathrm{~mm}^{-1}$. Consistent with the imperfectlywhite coloration of the skeletons, $R_{S}$ varied between 0.24 and 0.71 (relative to white standard, Table 1). Holobiont reflectance, $R_{H}$, varied between 0.02 and 0.26 prior to the initiation of stress (Fig. 1a, e).

Although corals are highly complex structures, the variability detected in repeated measurements of $\mu_{S, m}^{\prime}$, $R_{S}$, and $R_{H}$ is sufficiently small that we assume colonies can be characterized by mean values. The variability due to irregular surfaces and varying instrument positions is small, as is the coefficient of variation (COV), compared to the observed change in reflectance during bleaching. The average standard error of mean for $R_{H}$ is $<12 \%$ ( $\mathrm{n}=10$ measurements per ramet), and its COV is $38 \%$ (standard deviation relative to mean) while the observed change in reflectance during bleaching increases as much as $300 \%$ (Additional file 1: Figure S1a, f). This level of

Table 1 Optical, tissue, bleaching, and genetic data for individual corals

\begin{tabular}{|c|c|c|c|c|c|c|c|c|c|c|c|}
\hline \multirow{2}{*}{ Coral/Taxa } & \multicolumn{3}{|c|}{ Skeletal/Optics } & \multirow{2}{*}{$\begin{array}{c}\text { Colony } \\
\text { morphology }\end{array}$} & \multirow{2}{*}{$\begin{array}{l}\text { Tissue } \\
\text { (mm) }\end{array}$} & \multirow{2}{*}{$\begin{array}{c}\text { BRI } \\
\%\end{array}$} & \multicolumn{3}{|c|}{ Coral Genes } & \multicolumn{2}{|c|}{ Symbio. Genes } \\
\hline & $\mu_{s, m}^{\prime}\left(\mathrm{mm}^{-1}\right)$ & $R_{s}$ & $\mu_{s}{ }^{\prime}\left(m m^{-1}\right)$ & & & & $\mathrm{COI}$ & CytB & ITS & $23 S$ & ITS2 \\
\hline Merulina sp. & $\underset{\mu_{s, m}^{\prime}}{\text { low }} 1.53$ & 0.31 & 3.32 & Massive & 0.22 & $\begin{array}{c}43.79 \\
(g / 7)\end{array}$ & & & & C1 & C3u ${ }^{[75]}$ \\
\hline $\begin{array}{l}\text { Pocillopora } \\
\text { damicornis }\end{array}$ & 1.82 & 0.34 & 5.80 & $\begin{array}{c}\text { Medium } \\
\text { branching }\end{array}$ & 0.12 & $\begin{array}{c}41.33 \\
(\mathrm{sp} / 47)\end{array}$ & & & & D $1[77]$ & \\
\hline $\begin{array}{c}\text { Seriatopora } \\
\text { hystrix }\end{array}$ & 1.90 & 0.38 & 2.35 & Thin branching & 0.10 & $\begin{array}{l}61.46 \\
(\mathrm{sp} / 9)\end{array}$ & & & & & $\mathrm{D}^{\mathrm{a}}{ }^{[7 \mathrm{~B}}$ \\
\hline $\begin{array}{l}\text { Stylophora } \\
\text { pistillata }\end{array}$ & 2.80 & 0.44 & 4.26 & Thick branching & 0.97 & $\begin{array}{l}56.42 \\
(\mathrm{sp} / 9)\end{array}$ & & & & $\mathrm{C} 1$ & $C 8 a$ \\
\hline $\begin{array}{c}\text { Diploria } \\
\text { labyrinthiformis }\end{array}$ & 3.92 & 0.41 & 3.39 & Massive & $1.00^{[74]}$ & $\begin{array}{c}12.27 \\
(\mathrm{sp} / 26)\end{array}$ & & & & B1 & $\mathrm{B} 1^{[43]}$ \\
\hline $\begin{array}{l}\text { Turbinaria } \\
\text { reniformis }\end{array}$ & 3.94 & 0.53 & 3.48 & Laminar & 0.20 & $\begin{array}{l}33.96 \\
(g / 19)\end{array}$ & & & & $\mathrm{D1}$ & $\mathrm{D} 1 \mathrm{a}$ \\
\hline Goniopora sp. & 3.98 & 0.54 & 3.95 & Massive & $2.80^{[6]}$ & $\begin{array}{l}28.65 \\
(g / 28)\end{array}$ & & & & C1 & $\mathrm{C} 3 \mathrm{v}^{[75]}$ \\
\hline Favia favus & 4.36 & 0.24 & 3.98 & Massive & 1.00 & $\begin{array}{l}27.85 \\
(\mathrm{sp} / 6)\end{array}$ & & & & C1 & $\mathrm{C} 3 \mathrm{u}^{[75]}$ \\
\hline Montipora foliosa & 5.48 & 0.71 & 4.03 & Laminar & 0.27 & $\begin{array}{c}19.42 \\
(\mathrm{sp} / 10)\end{array}$ & & & & & $\mathrm{C} 15[75$ \\
\hline Montipora digitata & 5.80 & 0.42 & 3.92 & Thick branching & 0.32 & $\begin{array}{c}20.34 \\
(\mathrm{sp} / 11)\end{array}$ & & & & $\mathrm{C} 15$ & $C 15$ \\
\hline
\end{tabular}

Skeletal optical properties [skeletal scattering $\left(\mu_{S, m}^{\prime}\right)$, skeletal reflectance $\left(R_{S}\right)$ ], and bulk scattering $\left(\mu_{S}\right)$ ], tissue thickness (all measured directly, except those annotated with citations $[6,74])$, bleaching response index [BRI or the percent coral cover bleached and/or killed during mass bleaching events [18] used here as expected bleaching response for each taxon; parenthetical notation refers to genus- ( $\mathrm{g}$ ) or species-level (sp) estimations and the number of records that estimation is based upon], and genetic identity of corals and Symbiodinium assessed in experiment. Nucleotide sequences compared with Genbank (last accessed August 15, 2013) and reported as percent match (bar graphs) with accessions for coral mitochondrial cytochrome oxidase I (COI), cytochrome b (CytB), and nuclear internal transcribed spacer (ITS) genes; and Symbiodinium nuclear internal transcribed spacer region 2 (ITS2) and chloroplast 23S ribosomal (23S) genes. Shading of bars indicate the presence (solid black) or absence (diagonal lines) of the target species in Genbank, and low- (solid gray) or high-thermotolerance (stippled) of Symbiodinium [as reported in the literature (assuming C $3 u$ and C $3 v$ are similar to C 3 ) $[43,75-78]$ and indicated by parenthetical superscript number on the phylotype used to categorize thermotolerance] 


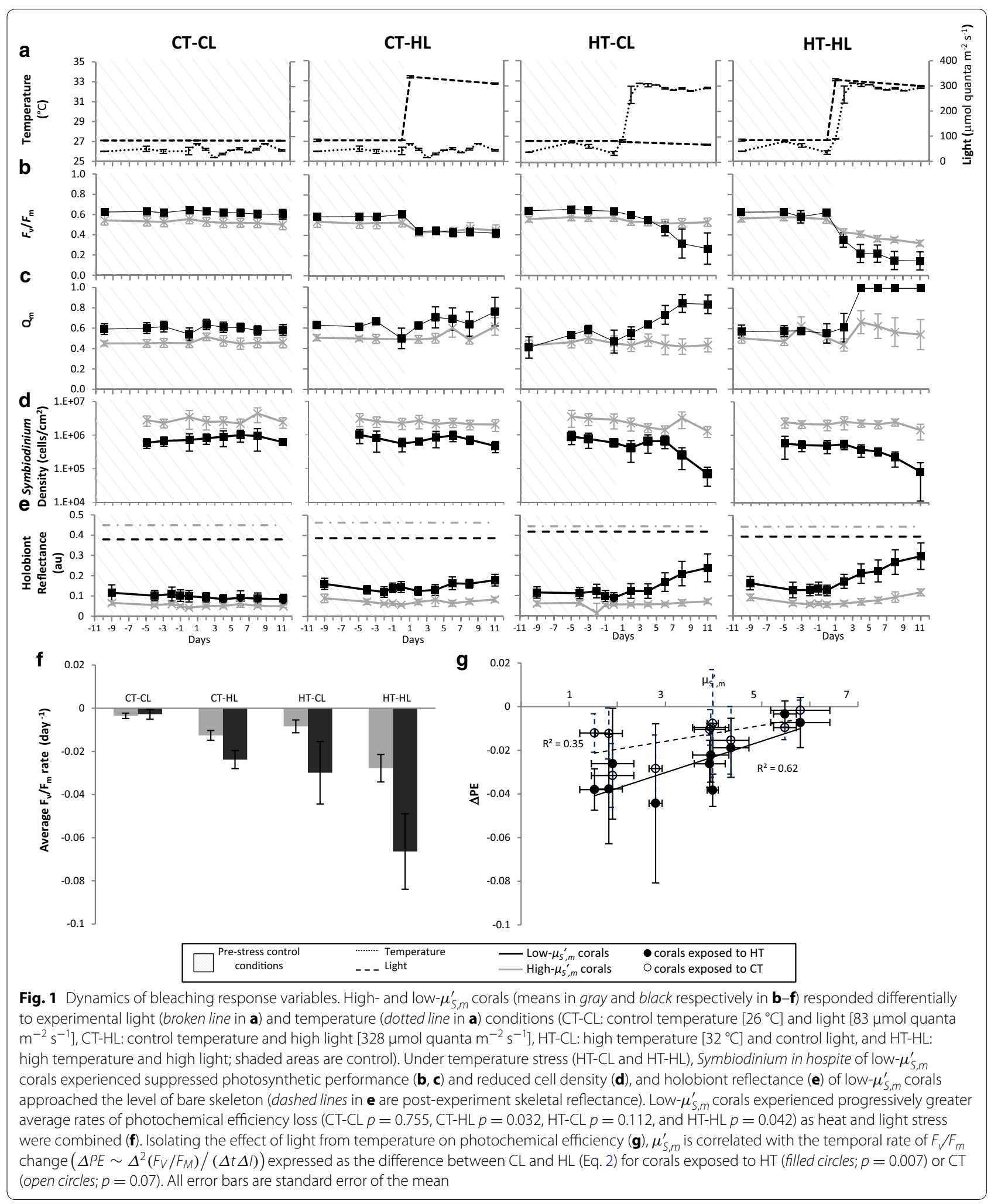


signal variability is sufficiently low to resolve changes in $R_{H}$ as small as $\sim 24 \%$. The COV of $\mu_{S, m}^{\prime}$ for coral skeletons has been previously determined to be similarly small, at $12 \%$ within a colony (assessing four areas from each of seven colonies) and $29.3 \%$ within a species (assessing 4-8 colonies representing each of seven species) [18].

\section{Low $\mu_{S, \mathrm{~m}}^{\prime}$ corals experience increased rates and severities of bleaching and remaining Symbiodinium experience increased rates and severities of light stress}

Corals in high temperature treatments (high temperature-control light: HT-CL, or high temperature-high light: HT-HL) experienced responses consistent with bleaching, with low- $\mu_{S, m}^{\prime}$ corals bleaching at greater rates and severities. Under the application of temperature (HT$\mathrm{CL}$ ) or light and temperature (HT-HL) stress all corals experienced significant (ANOVA, $p<0.05)$ reductions in Symbiodinium cell densities $(\rho)$ and increases in $R_{H}$, with the most severe responses among low- $\mu_{S, m}^{\prime}$ corals (Fig. 1; Additional file 2: Figure S2). Additionally, low- $\mu_{S, m}^{\prime}$ corals experienced significantly (ANOVA, $p<0.001$ ) greater decreases in Symbiodinium chlorophyll $a$ densities $(\mathrm{Chl} a$ ), with the greatest response occurring under the HT-HL treatment (Additional file 2: Figure S2). Exemplar $R_{H}$ spectra over the visible $(400-700 \mathrm{~nm})$ and near infra-red $(>700-800 \mathrm{~nm})$ regions are shown in (Additional file 1) Figure S1 for S. pistillata $\left(\right.$ low- $\left.\mu_{S, m}^{\prime}\right)$ and $M$. digitata (high- $\mu_{S, m}^{\prime}$ ) before and after combined thermaland light-stress was applied. As symbionts are lost during bleaching of $S$. pistallata, values of $R_{H}$ approached the values of $R_{S}$ (Fig. 1e; Additional file 2: Figure S1). Corals in the high light treatment alone (CT-HL) did not experience responses consistent with bleaching and observed differences in the dynamics of $R_{H}$, $\rho$, or Chl $a$ between low- and high- $\mu_{S, m}^{\prime}$ corals (Fig. 1; Additional file 2: Figure S2) are insignificant.

Symbiodinium that remained in hospite during bleaching experienced responses consistent with increasing light stress (i.e., corals under HT-CL, HT-HL), however Symbiodinium of low- $\mu_{S, m}^{\prime}$ corals experienced greater rates and severities of light stress (Fig. 1; Additional file 2:
Figure S2). Symbiodinium associated with low- $\mu_{S, m}^{\prime}$ corals experienced significantly suppressed photochemical efficiency $\left(F_{v} / F_{m}\right.$, linear mixed models, LMM, analysis) and elevated maximum-excitation pressure over PSII $\left(Q_{m}\right)$ (Fig. 1b, c, f). Specifically, the rate of reduction in photosynthetic performance $\left[\Delta\left(F_{V} / F_{m}\right) / \Delta t\right.$ and $\left.\Delta Q_{m} / \Delta t\right]$ was significantly greater for Symbiodinium of low- $\mu_{S, m}^{\prime}$ corals (clustered longitudinal analysis, $\mu_{S, m}^{\prime}$ group $\times$ day interaction term $p=0.016$ and 0.013 , respectively: Fig. 1b, c; Table 2) and photosynthetic function diverged between low- and high- $\mu_{S, m}^{\prime}$ corals at four and 2 days (for $F_{v} / F_{m}$ and $Q_{m}$ respectively) after stress initiation (marginal analysis, $p=0.013$ and 0.012 , respectively, Fig. $1 \mathrm{~b}$, c; Tables 3). Although non-photochemical quenching $\left(\Phi_{N P Q}\right)$ increased on average by 1.8 -fold for low- $\mu_{S, m}^{\prime}$ and 1.2 -fold for high- $\mu_{S, m}^{\prime}$ corals during bleaching, the dissipation of excess energy through non-photochemical mechanisms was not significantly different across highand low- $\mu_{S, m}^{\prime}$ corals (Additional file 2: Figure S2g).

\section{Symbiodinium of low $\mu_{S, m}^{\prime}$ corals experience increased rates of light absorption}

We developed an empirical model of light absorption by Symbiodinium in hospite by considering symbiont light-absorption $\left(I_{a}\right)$ as the sum of skeleton-independent absorption $\left(I_{a 1}\right)$ of downwelling light and skeletondependent absorption $\left(I_{a 2}\right)$ of reflected light (downwelling light not absorbed on the first pass and reflected by the skeleton back into coral tissue) [15-17]. The model relates $I_{a 1}$ and $I_{a 2}$ with parameters that were experimentally measured: skeletal reflectance, $R_{S}$, of the clean skeleton and holobiont reflectance, $R_{H}$, measured at different time points throughout the bleaching experiment.

The results of the model of Symbiodinium light absorption indicate that the estimated skeleton-dependent light absorbed per unit pigment $\left(I_{a 2} / \rho\right)$ and its rate $\left(\Delta\left(I_{a 2} / \rho\right) /\right.$ $\Delta t$ ) were several fold higher in low- $\mu_{S, m}^{\prime}$ corals (Fig. $2 \mathrm{a}-\mathrm{c}$, where average $\rho$ for low- and high- $\mu_{S, m}^{\prime}$ corals are concentrations of Chl $a$ in $\mu \mathrm{g} / \mathrm{cm}^{2}$, Additional file 2: Figure S2). This pattern remained (Fig. 2c) when the effect of downwelling light was isolated (subtracting $I_{a 2} / \rho$ determined

Table 2 Hierarchical linear mixed models (LMM) analysis of photosynthetic performance

\begin{tabular}{|c|c|c|c|c|}
\hline $\begin{array}{l}\text { Metric of bleaching } \\
\text { response }\end{array}$ & $\mu_{S, m}^{\prime}$ Cluster & Rate $\left(\right.$ day $\left.^{-1}\right)$ & $p$ value, rate & $\begin{array}{l}\mathrm{CLA} \mu_{S, m}^{\prime} \text {-day } \\
\text { interaction term } p \text { value }\end{array}$ \\
\hline \multirow[t]{2}{*}{$F_{V} / F_{m}$} & Low- $\mu_{S, m}^{\prime}$ & -0.0319 & $<0.001$ & 0.016 \\
\hline & High- $\mu_{S, m}^{\prime}$ & -0.0144 & 0.002 & \\
\hline \multirow[t]{2}{*}{$Q_{m}$} & Low- $\mu_{S, m}^{\prime}$ & 0.043 & $<0.001$ & 0.013 \\
\hline & High- $\mu_{S, m}^{\prime}$ & 0.011 & 0.19 & \\
\hline
\end{tabular}

Results of clustered longitudinal analysis (CLA) of high- and low- $\mu_{S, m}^{\prime}$ corals. Marginal analysis of $F_{v} / F_{m}$ performed with values normalized to initial because the dynamic inversion of values (seen at day 4 in Fig. 1b; Additional file 3: Figure S3) makes marginal analysis insensitive to absolute differences over time 
Table 3 Hierarchical linear mixed models (LMM) analysis of photosynthetic performance

\begin{tabular}{llll}
\hline $\begin{array}{l}\text { Metric } \\
\text { of bleaching } \\
\text { response }\end{array}$ & $\begin{array}{l}\text { Day after } \\
\text { application } \\
\text { of stress }\end{array}$ & $\begin{array}{l}\text { Difference } \\
\text { between } \\
\text { high- and low- } \mu_{s, m}^{\prime} \\
\text { groups }\end{array}$ & $p$ value \\
\hline $\begin{array}{l}F_{v} / F_{m} \text { (normalized to } \\
\text { initial values) }\end{array}$ & 0 & 0.0034 & 0.92 \\
& 2 & 0.054 & 0.074 \\
& 4 & 0.10 & 0.013 \\
$Q_{m}$ & 6 & 0.15 & 0.011 \\
& 0 & -0.057 & 0.22 \\
& 2 & -0.12 & 0.012 \\
& 4 & -0.19 & 0.003 \\
& 6 & -0.25 & 0.002
\end{tabular}

Results of marginal analysis of the photosynthetic performance $\left(F_{v} / F_{m}\right.$ and $\left.Q_{m}\right)$ of high- and low- $\mu_{s, m}^{\prime}$ corals. Marginal analysis of $F_{v} / F_{m}$ performed with values normalized to initial because the dynamic inversion of values (seen at day 4 in Fig. 1b; Additional file 3: Figure S3) makes marginal analysis insensitive to absolute differences over time

under CL from the HL treatment using Taylor expansion, Eq. 2 using $I_{a 2} / \rho$ as a metric instead of change in photochemical efficiency). As symbiont densities decrease, $I_{a 2} / \rho$ increases at a rate of $-\Delta\left(I_{a 2} /\left.\rho\right|_{H T H L}-I_{a 2} /\left.\rho\right|_{H T C L}\right) /$ $\Delta \rho$, which follows an inverse-power law function of $\mu_{S, m}^{\prime}$ $\left(\mathrm{r}^{2}=0.79\right)$, consistent with previously published data on flat-coral models [18]. Parameters chosen are valid at high per-cell pigment concentration, and $I_{a 2} / \rho$ significantly underestimates actual values as $\rho$ decreases. Because $\rho$ is reduced in low- $\mu_{S, m}^{\prime}$ corals during bleaching (Fig. 1d), our estimation of $I_{a 2}$ is conservative, and feedback effect is expected to be even more pronounced.

\section{Light and temperature dependent bleaching effects}

The light- or temperature-dependent bleaching effects were evaluated for one parameter in particular; the rate of reduction in photochemical efficiency of Symbiodinium with bleaching $(\triangle P E)$. In the case of light-dependent bleaching effect, $\triangle P E$ for corals exposed to $C L$ were subtracted from those exposed to HL for either control (i.e., CT-HL-CT-CL) or high (i.e., HT-HL-HT-CL) temperature (Eq. 2). Thereby, the effect of light on bleaching was determined by calculating the increased light stress $[\triangle P E(\mathrm{HL}-\mathrm{CL})]$ in the absence and presence of thermal stress. The rate of light-induced reduction in photosynthetic efficiency $\triangle P E$ is positively correlated with $\mu_{S, m}^{\prime}$, approaching 0 (no loss of $F_{v} / F_{m}$ with time) at the highest values of $\mu_{S, m}^{\prime}$, under high $\left(\mathrm{r}^{2}=0.62, p=0.007\right)$ or control $\left(\mathrm{r}^{2}=0.35, p=0.07\right)$ temperature (Fig. $\left.1 \mathrm{~g}\right)$. Taking a similar approach to isolate the effect of temperature on the rate of reduction in photosynthetic efficiency, $\triangle P E$ of corals exposed to $\mathrm{CT}$ were subtracted from those exposed to HT for either control (i.e., HT-CL-CT-CL) or high (i.e., HT-HL-CT-HL) light (Eq. 3). Temperature-induced loss of $F_{v} / F_{m}$ over time, $\triangle P E$, is not significantly correlated with $\mu_{S, m}^{\prime}\left(\mathrm{r}^{2}=0.18, p=0.23\right.$, Additional file 3: Figure S3a). Although all corals experienced some reduction in $F_{v} / F_{m}$ (during the 11 days of the experiment) under single stressor treatments (CT-HL and HT-CL), larger reductions were observed under combined heat and light stress with the greatest decline among low- $\mu_{S, m}^{\prime}$ corals (Fig. 1b).

\section{Factors that did not influence bleaching response}

The diversity of corals and symbionts included in these experiments permitted examination of the effects of several factors that have been previously described as determinants of bleaching response $\left(R_{S}\right.$, bulk- $\mu_{S}^{\prime}$, coral tissue thickness, colony morphology, Symbiodinium thermotolerance) and confounding factors of $\mu_{S, m}^{\prime}$ (i.e., parameters that correlated with $\mu_{S, m}^{\prime}$ : a priori physiological differences observed among the targeted species during baseline pre-stress measurements, including Symbiodinium and Chl $a$ densities, and photochemical efficiency). None of these factors were significantly correlated with the changes in photosynthetic performance observed in bleaching corals.

Corals examined included substantial diversity in $R_{S}$, bulk- $\mu_{S}^{\prime}$, coral tissue thickness, colony morphology, and Symbiodinium thermotolerances (Table 1). Skeletal reflectance was not significantly associated with changes in $F_{v} / F_{m}$ or $Q_{m}$ (Fig. 3b, c, f; Additional file 4: Figure S4; LMM, $p>0.15$ ). Bulk- $\mu_{S}^{\prime}$ (Table 1) was not significantly associated with the rate of reduction in photosynthetic efficiency $\triangle P E\left(\mathrm{r}^{2}=0.02, \mathrm{p}>0.5\right)$. The experimental corals included thin (S. hystrix), medium (P. damicornis), and thick branching (S. pistillata and M. digitata) colony morphologies, as well as laminar (M. foliosa and T. reniformis) and massive (Merulina sp., D. labyrinthiformis, Goniopora sp., and F. favus) forms; however colony morphology was not significantly associated with light$\left(\mathrm{r}^{2}=0.001, p>0.5\right)$ nor temperature- $\left(\mathrm{r}^{2}=0.02, p>0.5\right)$ dependent $\triangle P E$. Coral tissue thickness varied between 0.1 and $2.8 \mathrm{~mm}$ (Table 1), but was not significantly associated with light- $\left(\mathrm{r}^{2}=0.12, p>0.5\right)$ nor temperature$\left(\mathrm{r}^{2}=0.05, p>0.5\right)$ dependent $\triangle P E$. Experimental corals hosted some of the highest (C8a, C15, D1 and D1a) or lowest (B1 and, assuming similar to $\mathrm{C} 3, \mathrm{C} 3 \mathrm{u}$ and $\mathrm{C} 3 \mathrm{v}$ ) thermotolerance phylotypes known (Table 1). However Symbiodinium thermotolerance was not significantly associated with $F_{v} / F_{m}$ or $Q_{m}$ (LMM, $p>0.05$ ), and the observed trends have greater losses of photosynthetic performance among high-thermotolerance physiotypes (Fig. 3d, e, g; Additional file 5: Figure S5).

Physiological differences between low- and high- $\mu_{S, m}^{\prime}$ corals were detected in the absence of stress: low- $\mu_{S, m}^{\prime}$ corals had higher baselines for $F_{v} / F_{m}$ (Fig. 1b) and Chl $a$ (Additional file 3: Figure S3c) and lower baselines for 

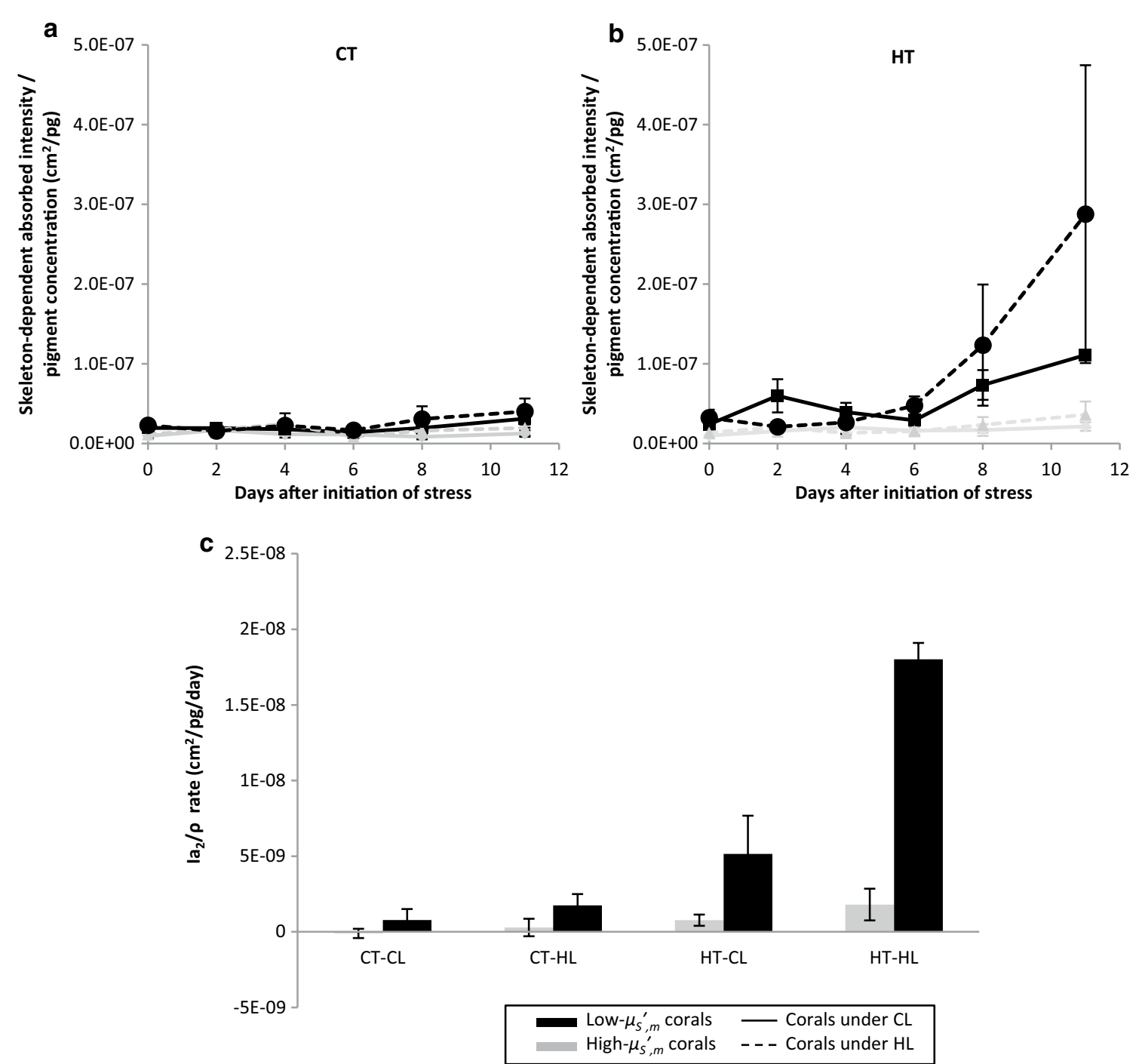

Fig. 2 Dynamics of modeled Symbiodinium light absorption in hospite due to skeletal backscattering $\left(\mu_{S, m}^{\prime}\right)$. Symbiodinium in hospite of high- ( gray line) and low- $\mu_{S, m}^{\prime}$ (black line) corals are (conservatively) predicted by an empirical model to have differential skeleton-dependent light absorption per unit pigment $\left(I_{a_{2}} / \rho\right)$. Under $\mathbf{a} C T$, the absorption of light in high- and low- $\mu_{S, m}^{\prime}$ corals is similar when exposed to $\mathrm{CL}$ (solid line) and HL (broken line). Under $\mathbf{b} \mathrm{HT}$, the absorption of light in low- $\mu_{S, m}^{\prime}$ corals is several times larger under either light condition, but the increase under $\mathrm{HL}$ is dramatic. Additionally, the increase in (conservatively) estimated temporal rates of light absorbed per unit pigment $\left(\Delta\left(I_{a 2} / \rho\right) / \Delta t\right)$ in low- $\mu_{S, m}^{\prime}$ corals $(b / a c k$ bars) is progressively greater as heat and light stress were combined (c). All abbreviations follow Fig. 1 and error bars are standard error of the mean

Symbiodinium density, $\rho$, (Fig. 1d) during monitoring prior to experimental manipulation ( $\mathrm{t}$ test, all $p<0.001$ ). Only baseline- $F_{v} / F_{m}$ had a significant correlation with $F_{v}$ $F_{m}$ (LMM, $\left.p=0.01\right)$, and also correlated with $\triangle P E$ under HT $\left(r^{2}=0.45\right)$. However, this correlation was unstable and primarily caused by a single datapoint (M. digitata), without which $\mathrm{r}^{2}$ dropped to 0.12 . Baseline $-F_{v} / F_{m}$ could not predict $\triangle P E$ under $C T\left(\mathrm{r}^{2}<0.07\right)$, and the difference between mean $\triangle P E$ of baseline-low- and baseline-high$F_{v} / F_{m}$ was not significant $\left(p>0.25\right.$ versus 0.007 for $\mu_{S, m}^{\prime}$ as the explanatory variable).

\section{Discussion}

Results of the bleaching experiment and empirical lightabsorption model are consistent with predictions of the optical feedback hypothesis. Bleaching corals with skeletal nanostructures that scatter light at relatively low $\mu_{S, m}^{\prime}$ experienced increased rates and severities of bleaching response $\left(\Delta R_{H}, \rho, \mathrm{Chl} a\right.$; Fig. $1 \mathrm{~d}$, e; Additional files 1 and 2: Figures S1, S2), light stress on retained Symbiodinium $\left(\Delta F_{v} / F_{m}, Q_{m}\right.$; Fig. 1), and amounts and rates of skeletondependent light absorption by remaining Symbiodinium $\left[\left(I_{a 2} / \rho\right)\right.$ and $\left(\Delta\left(I_{a 2} / \rho\right) / \Delta t\right)$; Fig. 2] relative to corals with 


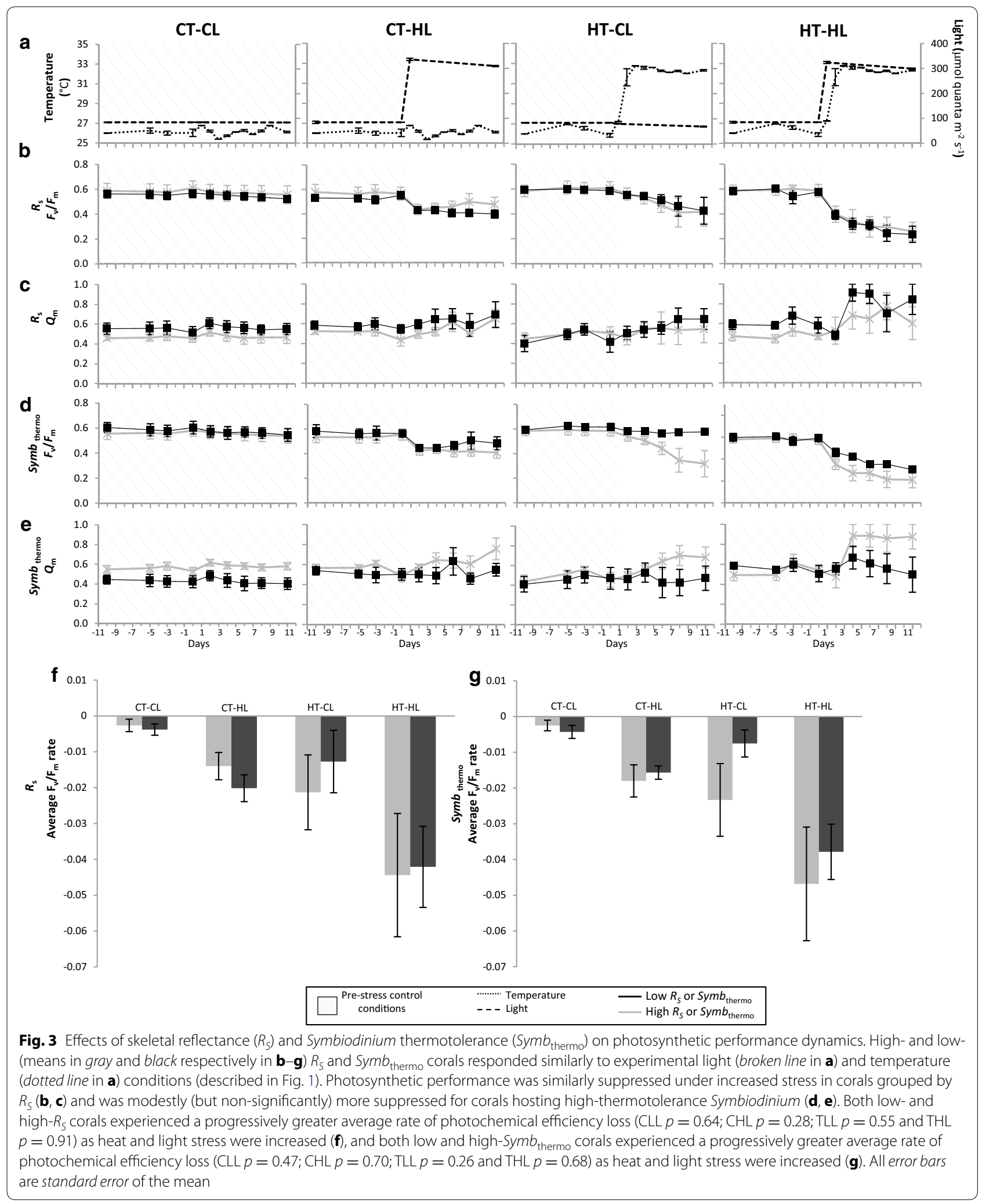


skeletal nanostructures that scatter light at relatively high $\mu_{S, m}^{\prime}$

\section{Low $\mu_{S, m}^{\prime}$ corals experience increased rates and severities of bleaching and remaining Symbiodinium experience increased rates and severities of light stress}

Although all corals experienced some response to increased temperature, differentially increased bleaching was detected among low- $\mu_{S, m}^{\prime}$ corals as early as day 2 (under HL-HT) and no later than day 6 (under CL-HT) after initiation of stress (Fig. 1; Additional file 2: Figure S2). Similarly, differentially decreased photosynthetic performance of retained Symbiodinium was nearly simultaneous with bleaching (within the sampling periods of the experimental design) and was detected among low$\mu_{S, m}^{\prime}$ corals as early as day 2 (under HL-HT) and no later than day 6 (under CL-HT) of the experiment (Fig. 1; Additional file 2: Figure S2).

Change in photosynthetic performance was evaluated by measuring changes in $F_{v} / F_{m}$ and $Q_{m}$ of all corals before and after the application of stress. $F_{v} / F_{m}$ indicates the proportion of potentially active PSII reaction centers under dark-adapted conditions [39] and significant decreases in $F_{v} / F_{m}$ over time under light- and heat-stress have been measured in bleaching corals (e.g., $[4,24,25])$. $Q_{m}[40,41]$ is sensitive to effective quantum yield $\left(\Phi_{P S I I}\right)$ oscillations as a result of the induction of multiple photoprotective pathways that compete for energy dissipation when light absorption exceeds photochemistry and indicates the proportion of active (or open) PSII reaction centers under peak irradiance [40]. Values approximating 0 indicate light-limitation with most reaction centers open, $\approx 1$ indicate photoinhibition with most reaction centers closed, and photoacclimation is indicated when $Q_{m}$ remains unchanged during suppressed photochemical efficiency [11, 12, 40]. Differential rates of divergence of photosynthetic performance (at day 4 for $F_{v} / F_{m}$ and day 2 for $Q_{m}$; Fig. 1) indicate that Symbiodinium associated with high- $\mu_{S, m}^{\prime}$ corals were experiencing photoacclimation $\left(Q_{m}\right.$ remains unchanged while $F_{v} / F_{m}$ decreases modestly) while those associated with low- $\mu_{S, m}^{\prime}$ corals were experiencing photoinhibition $\left(Q_{m}\right.$ approaches one, while $F_{v} / F_{m}$ decreases significantly); consistent with observations of bleaching corals $[11,40]$.

All corals dissipated excess energy through $\Phi_{N P Q}$ at similar levels (increase of 1.2-fold to 1.8-fold after thermal stress, Additional file 2: Figure S2g). This finding may seem unexpected as $\Phi_{N P Q}$ is mainly affected by photoprotective pathways (downregulation of PSII antenna pigments and the xanthophyll cycle) [42], and given the increased light stress experienced by low- $\mu_{S, m}^{\prime}$ corals, a greater increase in $\Phi_{N P Q}$ would be expected compared to high- $\mu_{S, m}^{\prime}$ corals. However, while suppressed $F_{v} / F_{m}$ and elevated $Q_{m}$ are often associated with severe bleaching response (e.g., [11, 12]), there is no consensus [43-46] that variation in $N P Q$ is indicative of resistance $[47,48]$ or sensitivity [44] to thermal stress and photoinhibition.

\section{Symbiodinium associated with low- $\mu_{s, m}^{\prime}$ corals absorb light at higher rates and amounts}

We developed an empirical model of light-absorption for in hospite Symbiodinium to test the assumption that the susceptibility of low- $\mu_{S, m}^{\prime}$ corals is driven by a feedbackloop between absorber loss (decrease in $\rho$ ) and the rate of light amplification increase, which exposes remaining symbionts to rapidly increasing light. The rate of light amplification increase is modeled as: $-\frac{d\left(I_{a} / I_{a 1}\right)}{d \rho}$; where $I_{a}$ is the fraction of incident light absorbed in tissue and $I_{a 1}$ is the fraction incident absorbed on its first pass through tissue. Change in the rate of light amplification increase is a consequence of a higher rate of light absorption per pigment due to skeletal reflectance, which is modeled as: $\frac{d\left(I_{a 2} / \rho\right)}{d \rho}$; where $I_{a 2}=I_{a}-I_{a 1}$ is the fraction of incident light not absorbed on the first pass, scattered by the skeleton back into the tissue and subsequently absorbed.

The empirical model of light-absorption for in hospite Symbiodinium is a generalization of prior models $[15,17]$, however it differentiates between downwelling (skeletonindependent) and reflected (skeleton-dependent) lightabsorption so that the effect of skeletal optical properties on light intensity experienced by symbionts is explicitly estimated and repeated passes of light between tissue and skeleton can be accounted for. The model expresses $I_{a}, I_{a 1}$ and $I_{a 2}$ through experimentally determined values for $R_{S}, R_{H}$, and three model parameters describing light transport properties of the holobiont $(\alpha, \beta, \gamma$; see "Methods"). Downwelling light that is not absorbed during the first pass can be returned to tissues by the skeleton, lost to absorption, or diffusely scattered out of the colony [17, $19,27,28]$ and may repeatedly pass between skeleton and tissue (i.e., aided by skeletal morphology; $[19,30])$. Thus, $I_{a 2}$ may be the result of multiple passes of light through tissue caused by multiple reflections of the skeleton [15, 17]. For a flat coral model (no multiple passes through tissue), and neglecting absorption of light reflected by the skeleton in tissue, our model (Eqs. 5, 6 and 7) converges to the approximate solution used to estimate the absorption of light based on holobiont and skeletal reflectance values $[15,29,49]$.

The estimated Symbiodinium light absorption indicates that the effect of $\mu_{S, m}^{\prime}$ on light absorption by Symbiodinium, $I_{a}$, is substantial. Skeleton-dependent light absorbed per unit pigment $\left(I_{a 2} / \rho\right)$ and its rate $\left(\Delta\left(I_{a 2} / \rho\right) /\right.$ $\Delta t$ ) were several fold higher in low- $\mu_{S, m}^{\prime}$ corals (Fig. $2 \mathrm{a}-$ c). This pattern was even more pronounced for combined 
light and temperature stress (Fig. 2b) and remained when the effect of downwelling light was isolated (Fig. 2c) (subtracting $I_{a 2} / \rho$ determined under CL from the $\mathrm{HL}$ treatment). Parameters $(\alpha, \beta, \gamma)$ chosen are valid at high per-cell pigment concentration and $\left(I_{a 2} / \rho\right)$ significantly underestimates actual values as $\rho$ decreases. Because $\rho$ is greatly reduced in low- $\mu_{S, m}^{\prime}$ corals during bleaching compared to high- $\mu_{S, m}^{\prime}$ (Fig. 1d), these calculations are expected to underestimate $I_{a 2}$, and the feedback effect is expected to be even more pronounced.

\section{$\mu_{S, m}^{\prime}$ is a robust predictor of light-dependent bleaching, but not of temperature-dependent bleaching}

By mathematically isolating the effect of light on bleaching from temperature and other confounding factors, including those unknown (light-dependent bleaching effect), we found that the rate of reduction in photochemical efficiency during bleaching $(\triangle P E)$ is associated with $\mu_{S, m}^{\prime}$, indicating that $\mu_{S, m}^{\prime}$ is one of the determinants of light-dependent bleaching severity. The rate of light-induced loss of $F_{v} / F_{m}$ is much more pronounced in low- $\mu_{S, m}^{\prime}$ corals; high- $\mu_{S, m}^{\prime}$ corals are nearly invariable under HT or CT conditions ( $\triangle P E$ approached 0; Fig. 1f, g). While $\mu_{S, m}^{\prime}$ was a robust predictor of light-dependent bleaching as it explained $62 \%$ of the variance in $\triangle P E$ for HT $\left(r^{2}=0.62, p=0.007\right.$, Fig. $\left.1 g\right)$, it was not a robust predictor of the temperature-dependent bleaching as $\mu_{S, m}^{\prime}$ explained only $18 \%$ of the variance in $\triangle P E$ for $\mathrm{HL}$ $\left(\mathrm{r}^{2}=0.18, p=0.23\right.$, Additional file 3: Figure S3a).

Heat and light stress have a compounding effect on bleaching response; differential sensitivity to light is amplified by temperature (Fig. 1f, g) as excess light generated by skeletal scattering may overwhelm photosystems impaired by thermal stress. Heat reduces the ability of Symbiodinium to utilize light in photosynthesis [4, 23, $25,50]$ and can uncouple energy absorption from photochemistry [23, 50]; resulting in excess energy independent of light increase. Therefore, Symbiodinium may perceive heat stress as an increase in excitation pressure over photosystem II $[23,50]$ and experience an increase in excess light as a result of an increase in temperature. In the absence of increased temperature stress, the effect of light-transport in the surface of the coral skeleton seems low, but once temperature increases and bleaching is initiated, the effect of light stress becomes remarkable, in particular for low- $\mu_{S, m}^{\prime}$ corals $\left(\mathrm{r}^{2}\right.$ for $\triangle P E\left(\mu_{S, m}^{\prime}\right)$ is two times lower for CT than HT; 0.35 and 0.62 , respectively, Fig. 1g). $\mu_{S, m}^{\prime}$ explained $35 \%$ of light-and temperature-dependent bleaching variance $\triangle P E$ for $\mathrm{HL}$ and $\mathrm{HT}$ $\left(\mathrm{r}^{2}=0.35, p=0.07\right.$, Additional file 3: Figure S3b). The ecological relevance of high- and low- $\mu_{S, m}^{\prime}$ remains to be fully understood, but current evidence points to very distinct ecological strategies. Skeleton deposited by corals is made of calcium carbonate nanograins (about 50-200 nm diameter) (e.g., [35]) that govern the scattering properties of the skeleton and present a fractal micro-morphology (i.e., structures between 30 and $1000 \mathrm{~nm}$ that have a similar degree of compactness [18]) likely reflective of their growth strategy and skeletogenesis. Corals with higher rates of linear extension, rather than skeletal infilling (typical of branching species), often have the lowest $\mu_{S, m}^{\prime}$ values and are typically thin branching, as opposed to corals with high- $\mu_{S, m}^{\prime}$ which often have higher skeletal density and are massive or thick branching [18]. A prior study of light scattering and skeletal fractality in 150 coral skeletons representing 94 coral taxa demonstrated that high and low- $\mu_{S, m}^{\prime}$ corals are important species in a variety of ecosystems. For example, S. hystrix and S. pistillata, two representatives of the Pocilloporidae family with low- $\mu_{S, m}^{\prime}$, can be frequently found in Central, Eastern, and Western Indo-Pacific reefs, while Porites lobata and Orbicella annularis of the Poritidae and Merulinidae families with high- $\mu_{S, m}^{\prime}$ are important species in Eastern Indo-Pacific and Caribbean reefs, respectively.

This study focused on the light scattering within skeleton and light absorbed by Symbiodinium in hospite, but did not evaluate light scattering within coral tissue which has been shown to significantly modulate light availability to symbionts. Light scattering causes lateral redistribution within tissue and increases light availability to symbionts $[19,28]$ while host fluorescent pigments $[33,51]$ or tissue contraction $[19,52]$ may reduce light stress by regulating light exposure and travel within tissue. Direct evidence for the optical feedback hypothesis would require in vivo measurements of Symbiodinium light-absorption rates as the coral undergoes bleaching and separation of skeleton-dependent effects, which has proven to be a technical challenge. However, combining the model of light absorbed by Symbiodinium in hospite developed in this study and light available to Symbiodinium within the coral tissue measured with light microsensors $[19,28,32]$ will improve models of the optics of intact corals. In fact, integrating within-tissue light scattering with skeletal scattering will allow for a comprehensive evaluation of the mechanisms of light scattering by skeleton and tissue in modulating light to symbionts and their role in bleaching response.

\section{Factors that did not influence bleaching response}

Neither $R_{S}$ (Fig. 3b, c, f; Additional file 4: Figure S4; LMM $p>0.15)$ nor $\mu_{S}^{\prime}\left(\mathrm{r}^{2}=0.02\right.$ for $\left.\triangle P E p>0.5\right)$ were significantly correlated with the severity of bleaching response. Light reflectance in coral skeletons is a complex process, and an important distinction must be made between $\mu_{S, m}^{\prime}$, which governs short-path light transport in the superficial skeletal layer, and the reduced scattering 
coefficient of the entire skeletal material, $\mu_{S}^{\prime}$. Short-path transport is primarily driven by scattering of nanograins and fiber bundles of the top $\sim 100 \mu \mathrm{m}$ and is less influenced by larger structures such as overall morphology of corallites, optical properties of deeper skeletal material, or absorption. Although $R_{S}$ includes the effect of shortpath light-transport, it is primarily determined by $\mu_{S}^{\prime}$, absorption, and overall coral morphology (see Additional file 6: Text S1.1). In agreement with this, $\mu_{S}^{\prime}$ assessed for the ten coral species in the present study was not a good predictor of bleaching response. This difference between $\mu_{S, m}^{\prime}$ and $\mu_{S}^{\prime}$ was also observed for 22 coral taxa [18]; modeling of the effect of $\mu_{S, m}^{\prime}$ on bleaching showed that the rate of increase of light enhancement with decrease of absorbers (microspheres modeling symbiont pigments) is inversely dependent on $\mu_{S, m}^{\prime}$. Although this model couldn't be applied to test the effect of $\mu_{S}^{\prime}$ on bleaching in thin (1-2 $\mathrm{mm}$ ) polished skeletal laminae, integrating sphere measurements of $\mu_{S}^{\prime}$ for 22 coral taxa showed no correlation with their bleaching susceptibility, further supporting observations of the current study [18].

Skeletal $R_{S}$ and $\mu_{S, m}^{\prime}$ affect coral physiology through two opposing light-modulation pathways: $\mu_{S, m}^{\prime}$ is inversely related to the rate of light amplification increase [18], $R_{S}$ is directly related to total light amplification [15, $17,30]$. Both $\mu_{S, m}^{\prime}$ and $R_{S}$ have the potential to increase light availability to symbionts [15-18,29] and exacerbate the bleaching response $[15,18]$. While our results identified a connection between $\mu_{S, m}^{\prime}$ and bleaching response, no correlation between $R_{S}$ or $\mu_{S}^{\prime}$ and $F_{v} / F_{m}$ was detected. Parallel to the hypothesis that the threshold for bleaching is determined by temperature increase rate [53], the threshold for light-enhanced bleaching appears to be determined by light-increase rate (associated with $\mu_{S, m}^{\prime}$ ) rather than the total light (associated with $R_{S}$ ).

Even though Symbiodinium thermotolerance (physiotype) has been shown to increase holobiont thermotolerance $\left(1-2{ }^{\circ} \mathrm{C}[54]\right)$ in a pattern that dominates current theory explaining differential bleaching susceptibility $[2$, 11-14], it was not associated with bleaching response in these experiments. While three associations had similar tolerances and susceptibilities, the most thermotolerant symbionts (D1, D1a, and C8a) were hosted by the most bleaching susceptible corals (P. damicornis, $S$. hystrix and S. pistillata $[5,6,18])$, and the most thermosensitive symbionts (B1, C3v, and $\mathrm{C} 3 \mathrm{u}$ ) were hosted by the most bleaching resistant corals (D. labyrinthiformis, Goniopora sp., and $F$. favus $[5,6,18]$ ); providing an opportunity to detect effects of symbiont physiotypes. Similar to recent evidence that differential bleaching susceptibility cannot be explained by symbiont thermotolerance alone [10, $55,56]$, no positive correlation between Symbiodinium thermotolerance and $F_{v} / F_{m}$ or $Q_{m}$ was detected (LMM, p > 0.5 and 0.05, respectively, Fig. 3d, e, g; Additional file 5: Figure S5). While thermotolerance is demonstrable within a single life-stage of an individual species [11] or in isolation [43], it is generally context-dependent within the physiological and physical properties of the coral host $[8,12,55,57]$ and environment $[12,58]$.

We evaluated potential confounding factors of $\mu_{S, m}^{\prime}$ : in the absence of stress, low- $\mu_{S, m}^{\prime}$ corals had lower Symbiodinium density, higher chlorophyll, and higher $F_{v} / F_{m}$ (t test, all $p<0.001$ ), but these factors were not found to significantly associate with differential bleaching severity among the ten studied coral species. While this study cannot rule out the existence of other unknown potential confounders that may correlate with $\mu_{S, m}^{\prime}$ and better explain the differential bleaching severity among these species, we have proposed a mechanism that explains the association of $\mu_{S, m}^{\prime}$ with differential bleaching severity.

\section{Conclusions}

Skeletal scattering was predictive of beaching susceptibility in these experiments and, if these results are representative of wider patterns, then they indicate that skeletal scattering is one of the key determinants of differential bleaching susceptibility. While symbionts associated with low- $\mu_{S, m}^{\prime}$ corals may receive less total light from their skeletons, they are predicted to experience a higher rate of (skeletally-derived) light increase once bleaching is initiated and absorbing bodies are lost; further precipitating the bleaching response. While $\mu_{S, m}^{\prime}$ explained $62 \%$ of the light-dependent variance in bleaching response, it was a poor predictor of the temperature-dependent variance and it explained $35 \%$ of the light- and temperature-dependent bleaching variance. Therefore, the remaining variance must be explained by other determinants of bleaching susceptibility. Symbiont phylotype can affect host physiology, holobiont fitness, and bleaching susceptibility [12, 54, 59]; higher symbiont densities per coral cell increase the risk of coral bleaching [55]; coral morphological and physiological properties modulate available light to the symbiont, determine early stress responses, and regulate symbiont photosynthetic demand for $\mathrm{CO}_{2}[8,30,57]$; within-tissue light scattering increases light availability to symbionts $[19,28]$ and may reduce the threshold for bleaching. The challenge now is to discern the contribution of the key determinants of bleaching susceptibility in order to identify the most effective management and remediation strategies to protect the remaining diversity of coral-Symbiodinium associations in a changing climate.

\section{Methods}

The predictions of the optical feedback hypothesis were experimentally assessed by monitoring the effects of 
differential $\mu_{S, m}^{\prime}$ on the dynamics of bleaching response for a diverse set of 10 corals and modelling skeletondependent light absorption by Symbiodinium from experimentally measured values of coral reflectance $\left(R_{H}\right.$ during bleaching and $R_{S}$ of bare skeletons). Low- $\mu_{S, m}^{\prime}$ corals should experience increased rates and severities of bleaching-response as indicated by dynamically decreased density of Symbiodinium $(\Delta \rho)$ and/or photosynthetic pigments per Symbiodinium cell $(\Delta \mathrm{Chl} a)$ and increased skeletal exposure $\left(\Delta R_{H}\right)$, increased rates and severities of light stress on the Symbiodinium which remain in hospite as indicated by photosynthetic performance $\left(\Delta F_{v} / F_{m}\right.$ and $\left.\Delta Q_{m}\right)$ and increased light absorption $\left(\Delta I_{a 2} / \rho\right)$. Because of the diversity of corals employed in this study, we assessed alternative factors (known and hypothesized) for their contribution to experimental bleaching responses, including physical properties of the host (skeletal reflectance and coral tissue thickness), and differences in Symbiodinium phylotype thermotolerance known from the historical record.

\section{Coral host and Symbiodinium types}

Colonies were prescreened for diversity of $\mu_{S, m}^{\prime}, R_{S}$, and Symbiodinium thermotolerance (Table 1). Coral were selected from live collections of Shedd Aquarium, Chicago, IL, USA (P. damicornis, S. hystrix, S. pistillata, T. reniformis, $M$. foliosa, and $M$. digitata originating from the Indo-pacific; and D. labyrinthiformis originating from Key West, Florida, USA) or obtained through A\&M Aquatics, Lansing, MI, USA (Goniopora sp., F. favus, and Merulina sp. originating from Jakarta, Indonesia or Fiji). All corals were property of Shedd Aquarium, who granted research approval through their institutional review board; none of the coral species are listed as endangered or threatened by the US Endangered Species Act. All colonies were acclimated under control conditions $\left(26^{\circ} \mathrm{C}\right.$ and $83.1 \pm 1 \mu \mathrm{mol}$ quanta $\mathrm{m}^{-2} \mathrm{~s}^{-1}$ on a 10/14 h light/dark cycle) 2-4 weeks prior to fragmentation and recovered 3-5 weeks under the same conditions. Ramets were created by cutting parent colonies into $32 \sim 1.5 \mathrm{~cm}^{2}$ explants with a wet tile-saw primed with artificial sea water $(37 \%$ salinity) and mounted to natural stone tiles using aquarium epoxy or ethyl 2-cyanoacrylate. Mounted corals where evenly distributed among four sectors in two aquaria. The tissue thickness of eight of the ten colonies were measured directly (reported as the mean of ten measurements) from size-standardized digital photos (using ImageJ version 1.47; NIH) of live colonies when cut in cross section, while the tissue thickness of D. labyrinthiformis and Goniopora sp. were estimated from published measurements (Table 1).

Holobiont tissue was scraped from skeletons and nucleic acids were extracted using standard protocols
[60]. Identification markers [Symbiodinium nuclear internal transcribed spacer region 2 (ITS2) and chloroplast $23 \mathrm{~S}$ ribosomal DNA (23S rDNA), and Scleractinia mitochondrial cytochrome oxidase I (COI), cytochrome b (CytB), and nuclear ITS] were selectively amplified by polymerase chain reaction (PCR) using standard reagents and the primers and annealing temperatures listed in Additional file 7: Table S1a and Additional file 6: Text S1.2. PCR products were separated by gel electrophoresis and directly sequenced using the amplification primers and identified by similarity (i.e., BLAST search) with GenBank accessions (Table 1). All DNA sequences created in this study are accessioned in GenBank as documentation of identity (Additional file 8: Table S1b). Morphological identification [61] was used for coral taxa novel to Genbank (Table 1). Thermotolerance of Symbiodinium phylotypes was designated following previous research (Table 1).

\section{Microscopic reduced light-scattering coefficient, $\mu_{S, m}^{\prime}$}

Microscopic-skeletal scattering $\left(\mu_{S, m}^{\prime}\right)$ was measured using low-coherence enhanced backscattering spectroscopy (LEBS) on corals cleaned with pressurized artificial seawater, soaked for $<12 \mathrm{~h}$ in $3 \%$ sodium hypochlorite, rinsed, and dried. We focused on short-propagating photons from the upper $\sim 100-200$ microns of skeletons to reduce the effects of 'bulk-scattering' properties [18]. The LEBS instrument has been previously described [62-64], and its application to coral ecology demonstrated [18]; but briefly, this method uses constructive interference of photons observed as an angular intensity cone centered in the backscattering direction to measure microscopicscattering through broadband partial spatial coherence illumination. The LEBS instrument uses linearly polarized collimated broadband illumination directed at the surface of a coral skeleton at $15^{\circ}$ angle of incidence, and light backscattered by the coral is collected using a lens, a polarizer, and an imaging spectrograph coupled with a CCD camera. The camera records a matrix of light-scattering intensities, $I_{L E B S}(\theta, \lambda)$, as a function of wavelength $\lambda(450-700 \mathrm{~nm})$ and backscattering angle $\theta$ ( -5 to 5 degrees). The spatial coherence length of illumination, $L s c$, was fixed at $\sim 57$ microns at $600 \mathrm{~nm}$ illumination. The reduced scattering coefficient of $\mu_{S}^{\prime}$ was measured on cleaned coral skeletons using the enhanced backscattering spectroscopy (EBS) method as previously described [64-66].

\section{Skeletal and holobiont reflectance $\left(R_{s}\right.$ and $\left.R_{H}\right)$}

Holobiont reflectance, $R_{H}$, is used to quantify bleaching: as Symbiodinium cell and photopigment density decrease, the skeleton becomes increasingly visible through host tissues and $R_{H}$ increases $[15,16,27,29]$. To prepare corals for $R_{S}$ measurements, tissue was removed 
from ramets with their skeletons remaining attached to their tiles so that they could be returned to the same location and orientation as they were during the collection of $R_{H}$ measurements. Preservation of the experimental conditions during measurement of $R_{S}$ insured that the intensity and direction of downwelling incident light was maintained and that $R_{S}$ would be comparable to $R_{H}$. Tissue was removed (by pressurized water), and preserved for Symbiodinium and pigment density analysis, and cleaned (as above) prior to measurement of $R_{S}$.

Reflectance, $R_{H}$ and $R_{S}$, were measured as spectral reflectance using an optical fiber (Thorlabs SFS200/220Y) attached to a spectrometer (Ocean Optics USB4000). This method uses the Lambertian nature of the diffusely reflected light to enable hand-held measurement. Radiant flux is independent of angle and distance for a flat Lambertian scattering surface, however coral surfaces are irregular and small signal variations occur in different fiber positions. To account for this variation, ten measurements were collected randomly across the geometry of the ramet for each time point and specimen. The fiber was held at a distance of 1-2 cm from the upper surfaces of the ramet, near normal to the illumination source, while simultaneously avoiding shading the interrogation spot. The aperture of the fiber and refractive index of the water determine the acceptance angle of light, therefore this method interrogates a 3-6 mm diameter spot which will include signal from polyp and coenosarc. Measurements were normalized to a white reflectance standard (PTFE, Ocean Optics) adjacent to each ramet. The raw spectral reflectance for $R_{S}$ and $R_{H}$ was not further processed (e.g., by applying low-pass filters that smooth signal averages of high frequencies, making the spectra appear less variable), as the signal to noise ratio is sufficiently high to distinguish changes in $R_{H}$ during bleaching (Additional file 6: Text S1.1).

\section{Experimental design}

The two experimental aquaria are $420 \mathrm{~L}(\sim 25 \mathrm{~cm}$ depth) recirculating unidirectional $(2.5-4 \mathrm{~cm} / \mathrm{s})$ baffled flumes, with the corals at $\sim 15 \mathrm{~cm}$ depth. The illuminating arrays (high color temperature that approximates sunlight) are divided by suspended shades to allow independent control of light conditions in each half of each aquarium. Explants were assigned to light sectors (8 ramets of each coral species) and randomly distributed within a sector to acclimate. See Additional file 9: Figure S6, and Additional file 6: Text S1.3 for details.

Stress was induced in three treatments (control remained static) by increasing the temperature to $32.3 \pm 0.5{ }^{\circ} \mathrm{C}$ (over 2 days) in one aquarium and light levels to $328.1 \pm 4.3 \mu \mathrm{mol}$ photons $\mathrm{m}^{2} / \mathrm{s}$ in half of both aquaria (dynamic photoinhibition has been observed at
200-400 $\mu \mathrm{mol}$ quanta $\mathrm{m}^{-2} \mathrm{~s}^{-1}$ [67] and a trial experiment showed chronic photoinhibition of these corals at $>400$ umol quanta $\mathrm{m}^{-2} \mathrm{~s}^{-1}$ with no increase in temperature). This established four conditions: (1) control temperature and control light (CT-CL: $26.2 \pm 1{ }^{\circ} \mathrm{C}$ at $83 \pm 1 \mu \mathrm{mol}$ photons $\mathrm{m}^{2} / \mathrm{s}$ ), (2) control temperature and high light (CT-HL: $26.2 \pm 1{ }^{\circ} \mathrm{C}$ at $328 \pm 4.3 \mu \mathrm{mol}$ photons $\mathrm{m}^{2} / \mathrm{s}$ ), (3) high temperature and control light (HT-CL: $32.3 \pm 0.5^{\circ} \mathrm{C}$ at $83 \pm 1 \mu \mathrm{mol}$ photons $\mathrm{m}^{2} / \mathrm{s}$ ), and (4) high temperature and high light (HT-HL: $32.3 \pm 0.5^{\circ} \mathrm{C}$ at $328 \pm 4.3 \mu \mathrm{mol}$ photons $\mathrm{m}^{2} / \mathrm{s}$ ) (Additional file 9: Figure S6). Ramets were assessed every second day for 10 days prior to stress induction and 11 days thereafter (Additional file 6: Text S1.3). Any ramets with necrotic tissue (1.3\% of replicates) were removed from the experiment. Bleaching response was evaluated by the dynamics of Symbiodinium and photopigment density, holobiont reflectance, and Symbiodinium photosynthetic performance.

\section{Symbiodinium photophysiology}

Symbiodinium photosynthetic performance was assessed through pulse-amplitude modulation (PAM) chlorophyll fluorometry with a $1.5 \mathrm{~mm}$ diameter optical fiber and the following instrument settings: measuring intensity 6 , saturation intensity 12 , saturation width 0.6 , and actinic light intensity 9 . Induction curves were collected with the $F_{0}{ }^{\prime}$-mode (far-red light) activated and a delay of $40 \mathrm{~s}$, a width of $20 \mathrm{~s}$, and a length of 13 cycles (Additional file 6: Text S1.4). Dark-adapted yield of photosystem II (PSII) was measured (where $F_{v} / F_{m}=F_{m}-F_{0} / F_{m}$ ) at 07:20-08:00 h (prior to sunrise) and induction curve analyses were performed at 09:00-13:00 $\mathrm{h}$ (at peak irradiance). Data for induction curves were collected through the steady state of $F^{\prime}$ and $F_{m}{ }^{\prime}$ and effective quantum yield $\left(\Phi_{P S I I}=F_{m}{ }^{\prime}-F^{\prime} / F_{m}\right)$, non-photochemical quenching $\left(\Phi_{N P Q}=F^{\prime} / F_{m}{ }^{\prime}-F^{\prime} / F_{m}\right)$ and non-regulated heat dissipation $\left(\Phi_{N O}=F^{\prime} / F_{m}\right)$ were calculated from steady state measurements where $\Phi_{P S I I}+\Phi_{N P Q}+\Phi_{N O}=1$ [42]. Photochemical efficiency, $F_{v} / F_{m}$, was used as a metric of bleaching response and has repeatedly been shown to decrease during bleaching [25, 43]. Symbiodinium exhibit $\Phi_{P S I I}$ oscillations when light absorption exceeds photochemistry [40], which is measured here as maximum excitation pressure over photosystem II, or $Q_{m}=1-\left[\left(\Phi_{\text {PSII at peak light }}\right) /\left(F_{v} / F_{m \text { at dawn }}\right)\right][40,41]$ (Additional file 6: Text S1.5).

\section{Symbiodinium and photosynthetic pigment density}

Symbiodinium cells were collected using pressurized seawater and the resulting slurry was concentrated by centrifugation before being divided into aliquots for hemocytometer cell counts (Additional file 6: Text S1.6) and high-performance liquid chromatography (HPLC) 
analysis of photosynthetic pigment identities and concentrations (Additional file 6: Text S1.7) using established procedures and gradients [68]. Surface area estimation of skeletons (for normalizing cell counts) were estimation using the single-dip wax method [69].

\section{Statistical analysis}

General linear model ANOVAs were performed in Minitab to test the effect of $\mu_{S m}^{\prime}$ on change in Symbiodinium cell and photosynthetic pigments density, $\Delta R_{H}$, $\Delta F_{v} / F_{m}$, or $\Delta Q_{m}$. Hierarchical linear mixed models (LMM) were applied in Stata 11.2 to account for the repeatedmeasures design [70] to assess the overall effect of treatment (time, light, and temperature) on bleaching response in the 11-day experiment (Additional file 6: Text S1.8). These analyses focused on the effect of potential explanatory variables $\left(\mu_{S m}^{\prime}, R_{S}\right.$, and Symbiodinum thermotolerance) on photophysiological response $\left(F_{v} / F_{m}\right.$ and $\left.Q_{m}\right)$.

\section{Determining light-dependent and temperature-dependent bleaching effects}

To determine the effect of light and temperature on bleaching separately, we used Taylor Series Expansion to mathematically isolate factors of interest (effect of light or temperature on temporal rates of $F_{v} / F_{m}$ decrease) and cancel out known and unknown confounders across conditions because the physical conditions of the live animal experiment cannot be made precisely identical across all ramets. For example, potential confounders such as differential tissue thickness and localized morphologyinduced flow diversity among explants of the same colony could alter mass transfer across the diffuse boundary layer and affect bleaching response [16, 71-73]; these factors cannot be fully controlled among such a large number of ramets. However, they can be mathematically cancelled out from all conditions by subtracting the difference between temporal rates of $F_{v} / F_{m}$ decrease $(P E)$ under control and stress conditions for each environmental factor (light or temperature).

To determine the light-dependent bleaching effect, we examined the difference between $P E$ under control and high light conditions. For a given ramet $i$, the temporal rate of $F_{v} / F_{m}$ decrease, $P E_{i}=\frac{\Delta\left(F_{V} / F_{m}\right)_{i}}{\Delta t}$, where $t$ is time after the initiation of bleaching, was expressed as the first order Taylor expansion over temperature, light intensity, and potential confounding (including unknown) factors:

$$
P E_{i}(T, I)=X_{i}+\left.\Delta T \frac{\partial P E_{i}}{\partial T}\right|_{T_{1}, I_{1}}+\left.\Delta I \frac{\partial P E_{i}}{\partial I}\right|_{T_{1}, I_{1}},
$$

where $\Delta T$ is the difference between experimental temperature $T$ and control $T_{1}, \Delta I$ is the difference between experimental light intensity $I$ and control $I_{1}$, and $X_{i}$ accounts for all other conditions (e.g., localized flow rates, without assuming that they are identical across ramets). To mathematically isolate the effect of light from temperature and confounding factors, $P E$ values for corals exposed to CL $\left(I=I_{1} \equiv I_{C L}\right)$ were subtracted from corals exposed to HL $\left(I=I_{2} \equiv I_{H L}\right)$ for either control ( $\left.T=T_{1}\right)$ or high $\left(T=T_{2}\right)$ temperature:

$$
\begin{aligned}
\Delta P E_{i}\left(T_{j}\right) & =P E_{i}\left(T_{j}, I_{H L}\right)-P E_{i}\left(T_{j}, I_{C L}\right) \\
& =\left.\left.\left(I_{H L}-I_{C L}\right) \frac{\partial P E_{i}}{\partial I}\right|_{T_{j}, I_{C L}} \propto \frac{\partial^{2}\left(F_{V} / F_{m}\right)_{i}}{\partial t \partial I}\right|_{T_{j}},
\end{aligned}
$$

where index $j$ indicates either high $(j=2)$ or control $(j=1)$ temperature environment. In the first order approximation, this differential quantity $\triangle P E_{i}$ is independent of factors not directly related to illumination.

Similarly, to mathematically isolate the effect of temperature from light and confounding factors (temperature-dependent bleaching effect), $P E$ values for corals exposed to CT were subtracted from corals exposed to HT:

$$
\begin{aligned}
\Delta P E_{i}\left(I_{j}\right) & =P E_{i}\left(T_{H T}, I_{j}\right)-P E_{i}\left(T_{C T}, I_{j}\right) \\
& =\left.\left.\left(T_{H T}-T_{C T}\right) \frac{\partial P E_{i}}{\partial T}\right|_{T_{C T}, I_{j}} \propto \frac{\partial^{2}\left(F_{V} / F_{m}\right)_{i}}{\partial t \partial T}\right|_{I_{j}},
\end{aligned}
$$

where index $j$ indicates either $\operatorname{HL}(j=2)$ or $\mathrm{CL}(j=1)$ environment.

$\triangle P E$ was analyzed as a function of potential explanatory variables (potential determinants of bleaching response; $\mu_{S m}^{\prime}, R_{S}$, tissue thickness, and Symbiodinium thermotolerance) and confounders of $\mu_{S m}^{\prime}$ (initial $F_{v} / F_{m}$, initial Symbiodinium and chl $a$ density), thereby removing differences in bleaching response that are not explicitly related to light.

\section{Skeleton-dependent light absorption model}

We developed a novel model of Symbiodinium light absorption, which, in comparison to existing models, accounts for skeleton-driven absorption and multiple reentry effects. Incident light absorption by Symbiodinium (fraction $I_{a}$ ) can be viewed as the result of absorption of downwelling light (fraction $I_{a 1}$ of the incident light) and skeleton-dependent absorption (fraction $I_{a 2}=I_{a}-I_{a 1}$ ) of light reflected by the skeleton [15-17]. Light that is not absorbed in the first pass $\left(1-I_{a 1}\right)$ can be reflected by the skeleton back into the tissue, lost to skeletal absorption, or diffusely scattered out of the colony [17, 19, 27, 28]. This process may involve multiple passes of light through tissue due to multiple reentries of unabsorbed light back into the skeleton and subsequent reflections by the skeleton $[15$, 
17]. Because direct quantification of light absorption by pigments in live corals is not currently possible, we developed an empirical model relating $I_{a 1}$ and $I_{a 2}$ with experimentally measurable parameters $R_{S}$ and $R_{H}$.

Starting with balance equations for $R_{H}$ and $I_{a}$, we solve for $I_{a 1}$ and $I_{a 2}$ [see Additional file 6: Text S1.9 for detailed derivation using equations (4) through (7)]:

$$
\begin{aligned}
& R_{H}=R_{1}\left(1-I_{a 1}\right)\left(1-a_{2}\right), \\
& I_{a 1}=\frac{1}{2 \alpha}\left(1+\alpha-\sqrt{(1+\alpha)^{2}-4 \alpha\left(1-\beta R^{\prime}\right)}\right), \\
& I_{a}=I_{a 1}+\left(1-I_{a 1}\right) R_{1} a_{2}+\left(1-I_{a 1}\right) \gamma\left(R_{s}-R_{1}\right), \\
& I_{a 2}=I_{a}-I_{a 1}=\left(1-I_{a 1}\right)\left(\frac{\alpha}{\beta} I_{a 1}+\gamma \frac{\beta-1}{\beta}\right) R_{S},
\end{aligned}
$$

where $R^{\prime}=R_{H} / R_{S}, \beta=R_{S} / R_{1}, \alpha=a_{2} / I_{a 1}$ with $R_{1}$ the fraction of unabsorbed light that is leaving the holobiont after being reflected by the skeleton back into tissue including all reentries and $a_{2}$ the fraction of this reflected light that is absorbed by the pigments in the tissue, and $\gamma$ is the fraction of light that is absorbed by tissue through processes other than $I_{a 1}$ or $a_{2}$ divided by $\left(R_{S}-R_{1}\right)$.

Coefficients $\alpha, \beta$, and $\gamma$ depend on coral morphology, its optical properties, and the concentration of absorbing pigments in tissue (see Additional file 6: Text S1.9 for detailed explanation). Coefficient $\alpha(>1)$ describes the amplification of light absorption due to elongation of light paths through the tissue caused by diffuse skeletal reflection of unabsorbed downwelling light, which is why $\alpha$ increases as the concentration of absorbing pigments decreases. Coefficients $\beta$ and $\gamma$ are related to the non-flatness of the skeleton and account for the reentry effect. In the special case of no reentry (flat coral model), $\beta=\gamma=1$ and $1<\alpha \leq 2$. Non-flat skeletons can create $\alpha>2$ due to multiple reentry [15] and $\beta>1$ and $\gamma<1$ for non-flat geometries. If reentry is neglected, Eq. 7 for $I_{a}$ converges to the solution that has been conventionally used to estimate the light absorption based on holobiont and skeletal reflectances [15, 29, 49], $I_{a} \approx 1-R^{\prime}$, if one of the following two conditions is satisfied: $I_{a 2}$ can be neglected (most of the absorption is due to the downwelling light) or $R_{S}=1$. Even though $\alpha, \beta$, and $\gamma$ depend on concentration and the optical properties of the skeletons, the model can still be used to estimate the range of $I_{a 1}$ and $I_{a 2}$. Indeed, $I_{a 2}$ increases with $\alpha$ (e.g., as symbionts leave). Thus, we can obtain the lower bound on $I_{a 2}$ by using Eqs. (5) and (7) with $\alpha=\beta=\gamma=1$.

\section{Consent to publish}

Express written informed consent has been granted for publication of Figure S6.

\section{Availability of data and materials}

All supporting data are submitted to GenBank (accession numbers KF492657-KF492693) or are included as additional files.

\section{Additional files}

\begin{abstract}
Additional file 1: Figure S1. Dynamics of holobiont reflectance $\left(R_{H}\right)$. Panels a-f are aligned into columns defined by light (broken line in a) and temperature (dotted line in a) conditions (described in Figure S1). Response of an exemplar low- $\mu_{S, m}^{\prime}$ coral (S. pistillata) through (b) time series photos of explants, (c) spectral $R_{H}$, and (f) means (black line) and standard errors of the 10 random measurements collected to estimate $R_{H}$ normalized to its skeleton reflectance at $675 \mathrm{~nm}$. Response of an exemplar high- $\mu_{S, m}^{\prime}$ coral (M. digitata) through (d) time series photos of coral explants, (e) spectral $R_{H}$ and (f) means (gray line) and standard errors of the 10 random measurements collected to estimate $R_{H}$ normalized to its skeleton reflectance at $675 \mathrm{~nm}$. Spectral skeletal reflectance $\left(R_{S}\right)$ in panels $\mathrm{c}$ and e shown to contextualize $R_{H}$ with the limit of $R_{S}$ values in the visible spectrum where photopigments have substantial absorption (e.g., $675 \mathrm{~nm}$, chlorophyll a absorption peak); for wavelengths > $700 \mathrm{~nm}$, the limit of $R_{H}$ may be greater than $R_{S}$. As corals bleached and less than $10 \%$ of symbionts remained associated with the host, $R_{H}$ approached the values of $R_{S}$.
\end{abstract}

Additional file 2: Figure S2. Dynamics of bleaching response variables for corals grouped by $\mu_{s, m}^{\prime}$. Panels (a-h) aligned into columns defined by experimental conditions $\left(\mathrm{CT}-\mathrm{CL}\right.$ : control temperature $\left[26^{\circ} \mathrm{C}\right]$ and light [ $83 \mu \mathrm{mol}$ quanta $\mathrm{m}^{-2} \mathrm{~s}^{-1}$ ], CT-HL: control temperature and high light $\left[328 \mu \mathrm{mol}\right.$ quanta $\left.\mathrm{m}^{-2} \mathrm{~s}^{-1}\right], \mathrm{HT}-\mathrm{CL}$ : high temperature $\left[32^{\circ} \mathrm{C}\right]$ and control light, and HT-HL: high temperature and high light; shaded areas are control). Responses of high- (gray line) and low- $\mu_{S, m}^{\prime}$ (black line) corals for (a) holobiont reflectance (dashed lines are the corresponding post-experiment skeletal reflectance), (b) Symbiodinium cell density, (c) chlorophyll a density per Symbiodinium cell, (d) maximal photosynthetic efficiency, (e) effective quantum yield of photosystem II, (f) excitation pressure over photosystem II, (g) non-photochemical quenching, and (h) non-regulated heat dissipation. All error bars are standard error.

Additional file 3: Figure S3. $\mu_{S m}^{\prime}$ and temperature- and light-induced bleaching response. $\mu_{S, m}^{\prime}$-specific temporal rate of $F_{V} / F_{m}$ change $\left(\triangle P E \sim \Delta^{2}\left(F_{V} / F_{M}\right) /(\Delta t \Delta R)\right)$ after stress-initiation is expressed as (a) the difference between $C T$ and $\mathrm{HT}$ conditions (Eq. 3) for corals exposed to HL (filled circles; $p=0.22$ ) and $\mathrm{CL}$ (open circles; $p=0.44$ ), isolating the effect of temperature on bleaching response, and (b) $\triangle P E$ for $\mathrm{HL}$ and $\mathrm{HT}$ conditions $(p=0.07)$, where both temperature- and light-dependent bleaching response is evaluated. Although $\mu_{S, m}^{\prime}$ predicts light-dependent bleaching $\left(r^{2}=62.3\right.$ and $p=0.007$, Fig. $\left.1 \mathrm{~g}\right)$, it is a weak predictor of temperaturedependent bleaching and light- and temperature-dependent bleaching.

Additional file 4: Figure S4. Dynamics of bleaching response variables for corals grouped by skeletal reflectance $\left(R_{S}\right)$. Panels (a-h) aligned into columns defined by experimental conditions (described in Figure S3). Responses of high- (gray line) and low- $R_{S}$ (black line) corals for (a) holobiont reflectance (dashed lines are the corresponding post-experiment skeletal reflectance), (b) Symbiodinium cell density, (c) chlorophyll a density per Symbiodinium cell, (d) maximal photosynthetic efficiency, (e) effective quantum yield of photosystem II, (f) excitation pressure over photosystem II, (g) non-photochemical quenching, and (h) non-regulated heat dissipation. All error bars are standard error.

Additional file 5: Figure S5. Dynamics of bleaching response variables for corals grouped by Symbiodinium thermotolerance $\left(\right.$ Symb $b_{\text {thermo }}$ ). Panels $(a-h)$ aligned into columns defined by experimental conditions (described

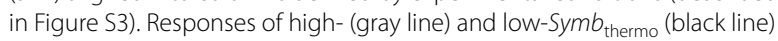
corals for (a) holobiont reflectance (dashed lines are the corresponding post-experiment skeletal reflectance), (b) Symbiodinium cell density, (c) chlorophyll a density per Symbiodinium cell, (d) maximal photosynthetic 
efficiency, (e) effective quantum yield of photosystem II, (f) excitation pressure over photosystem II, (g) non-photochemical quenching, and (h) non-regulated heat dissipation. All error bars are standard error.

Additional file 6. Supporting Text. Supporting methods (1) and supporting references (2).

Additional file 7: Table S1a. Nucleotide sequencing. Primers [79-82] and annealing temperatures used for polymerase chain reaction amplification and nucleotide sequencing.

Additional file 8: Table S1 b. Nucleotide sequencing. GenBank accession numbers of genes sequenced in this study.

Additional file 9: Figure S6. Experimental setup. High temperature aquarium encompassing the $\mathrm{HT}-\mathrm{CL}$ and $\mathrm{HT}-\mathrm{HL}$ conditions on day 11 of the bleaching experiment (a); black divider separating light arrays, flow baffles, and mounted corals can be seen. Collecting PAM measurements in the control temperature aquarium within the $\mathrm{CT}-\mathrm{CL}$ condition (CT-HL on the opposite side of black divider) on day 11 of the bleaching experiment (b); positioning of the PAM instrument probes above the coral explants mounted on stone tiles can be seen. Close up of probe holder (custom-machined acrylic block that ensures probes are returned to each explant in the same three-dimensional geometry as previous measurements) supported at a $23^{\circ}$ angle by square PVC post (gray) attached to the coral-mounting tile (c); probes are (left to right) temperature, $\mathrm{O}_{2}$ (data not reported), and PAM fiber optic immobilized in a black PVC tube. Control temperature aquarium encompassing the CT-CL and CT-HL conditions (HT aquarium in background) during acclimation period prior to prescreening and fragmentation (d); photograph taken before installation of the flow baffles and black divider separating light arrays. Hand-held optical fiber attached to a spectrometer to measure $R_{H}$ (and $R_{S}$ of cleaned skeleton) with white reflectance standard visible in the background (e). Consent to publish these images has been documented.

\section{Abbreviations}

Chl a: chlorophyll a density; COV: coefficient of variation; CT-CL: control temperature-control light; $\mathrm{CT}-\mathrm{HL}$ : control temperature-high light; EBS: enhanced backscattering spectroscopy; $F^{\prime}$ : fluorescence yield in actinic light; $F_{m}$ : maximum fluorescence yield; $F_{m}$ ': maximum fluorescence yield in actinic light; $F_{v}$ : maximum variable fluorescence yield; $F_{v} / F_{m}$ : photochemical efficiency; $F_{0}$ : minimum fluorescence yield; $F_{0}{ }^{\prime}$ : minimum fluorescence yield in light-acclimated state; $\mathrm{HT}-\mathrm{CL}$ : high temperature-control light; $\mathrm{HT}$-HL: high temperature-high light; I: light intensity; I: Symbiodinium light-absorption; $I_{a 1}$ : skeleton-independent light-absorption; $I_{a}$ : skeleton-dependent lightabsorption; LEBS: low-coherence enhanced backscattering spectroscopy; LMM: linear mixed models; PAM: pulse-amplitude modulation chlorophyll fluorometry; $P E$ : temporal rate of $F_{V} / F_{m}$ (photochemical efficiency) reduction; PSII: photosystem II; $Q_{m}$ : maximum-excitation pressure over photosystem II; $R_{H}$ : holobiont reflectance; $R_{s}$ : diffuse reflectance of light from coral skeletons; T: temperature; $a$ : amplification of light absorption due to elongation of light paths through the tissue caused by diffuse skeletal reflection of unabsorbed downwelling light; $\beta$ : accounts for the reentry effect; $\gamma$ : is the fraction of light that is absorbed by tissue through processes other than $I_{a 1}$ or $a_{2}$ divided by $\left(R_{S}-R_{1}\right) ; \mu_{S, m}^{\prime}:$ microscopic reduced-scattering coefficient or the inverse of the distance a short-path length photon travels before randomization; $\mu_{\varsigma}^{\prime}$ or bulk- $\mu_{s}^{\prime}$ : reduced-scattering coefficient or the inverse of the distance a photon travels before randomization; $\rho$ : Symbiodinium cell density; $\Phi_{\text {psII }}$ : effective quantum yield of photosystem II; $\Phi_{N O}$ : non-regulated heat dissipation; $\Phi_{N P Q}$ : non-photochemical quenching.

\section{Authors' contributions}

TDS ED JDR VB LAM conceived and designed the experiments. VPS AJR HWG BJK JDR VB measured and analyzed optical properties of corals. TDS ED JH JT LAM performed the experiments. TDS JT performed PAM. HWG EMV performed cell counts and surface area estimates. ED AAG performed HPLC. TDS AG BCB MEW JD VB LAM analyzed the data. MWW KS SL MS GP VB LAM contributed expertise/reagents/materials/animal care/analysis tools. TDS MEW VB LAM prepared the manuscript. All authors read and approved the final manuscript.

\section{Author details}

${ }^{1}$ Department of Civil and Environmental Engineering, Northwestern University, 2145 Sheridan Road, Evanston, IL 60208, USA. ${ }^{2}$ Department of Zoology, Field Museum of Natural History, 1400 South Lake Shore Drive, Chicago, IL 60605, USA. ${ }^{3}$ Department of Biomedical Engineering, Northwestern University, 2145 Sheridan Road, Evanston, IL 60208, USA. ${ }^{4}$ Keck Biophysics Facility, Northwestern University, 633 Clark Street, Evanston, IL 60208, USA. ${ }^{5}$ Fishes Department, John G. Shedd Aquarium, 1200 South Lake Shore Drive, Chicago, IL 60605, USA. ${ }^{6}$ Division of Water Resource Management, Florida Department of Environmental Protection, 2600 Blair Stone Road, Tallahassee 32399, USA.

\section{Acknowledgements}

We thank I. Berzins, C. Knapp, M. Moskalick, and L. Nesslar of Shedd Aquarium for helpful discussion, specimens, and engineering; F. Hussain, P. Humecki, J. Juranek, R. Pelkar, and A. Vadlamanu for assisting with experiments; K. Feldheim, P. Sierwald, and S. Ware of the Field Museum for expertise in the molecular and microscopy labs. This research was supported by National Science Foundation (EFRI-1240416 and CBET-1249311), National Institutes of Health (EB 003682), and MacArthur Foundation (to Encyclopedia of Life), and is dedicated to the memory of Corey M. Janczak.

\section{Competing interests}

The authors declare that they have no competing interests.

Received: 19 August 2015 Accepted: 12 February 2016

Published online: 21 March 2016

\section{References}

1. Wilkinson C. Status of the coral reefs of the world: 2008. Townsville: Global Coral Reef Monitoring Network and Reef and Rainforest Research Centre; 2008.

2. Baker AC, Glynn PW, Riegl B. Climate change and coral reef bleaching: an ecological assessment of long-term impacts, recovery trends and future outlook. Estuar Coast Shelf S. 2008;80:435-71.

3. Hoegh-Guldberg O, Mumby PJ, Hooten AJ, Steneck RS, Greenfield P, Gomez E, et al. Coral reefs under rapid climate change and ocean acidification. Science. 2007:318:1737-42.

4. Lesser MP, Farrell JH. Exposure to solar radiation increases damage to both host tissues and algal symbionts of corals during thermal stress. Coral Reefs. 2004;23:367-77.

5. Marshall PA, Baird AH. Bleaching of corals on the Great Barrier Reef: differential susceptibilities among taxa. Coral Reefs. 2000;19:155-63.

6. Loya Y, Sakai K, Yamazato K, Nakano Y, Sambali H, van Woesik R. Coral bleaching: the winners and the losers. Ecol Lett. 2001;4:122-31.

7. van Woesik R, Sakai K, Ganase A, Loya Y. Revisiting the winners and the losers a decade after coral bleaching. Mar Ecol Prog Ser. 2011:434:67-76.

8. Wooldridge SA. Differential thermal bleaching susceptibilities amongst coral taxa: re-posing the role of the host. Coral Reefs. 2014;33:15-27.

9. Middlebrook R, Hoegh-Guldberg O, Leggat W. The effect of thermal history on the susceptibility of reef-building corals to thermal stress. J Exp Biol. 2008:211:1050-6.

10. Bellantuono AJ, Hoegh-Guldberg O, Rodriguez-Lanetty M. Resistance to thermal stress in corals without changes in symbiont composition. P Roy Soc B Biol Sci. 2012;279:1100-7.

11. Abrego D, Ulstrup KE, Willis BL, van Oppen MJH. Species-specific interactions between algal endosymbionts and coral hosts define their bleaching response to heat and light stress. P Roy Soc B Biol Sci. 2008;275:2273-82.

12. Mieog JC, Olsen JL, Berkelmans R, Bleuler-Martinez SA, Willis BL, van Oppen MJH. The roles and interactions of symbiont, host and environment in defining coral fitness. PLoS One. 2009;4:e6364.

13. Jones AM, Berkelmans R, van Oppen MJH, Mieog JC, Sinclair W. A community change in the algal endosymbionts of a scleractinian coral following a natural bleaching event: field evidence of acclimatization. P Roy Soc B Biol Sci. 2008;275:1359-65.

14. Silverstein RN, Cunning R, Baker AC. Change in algal symbiont communities after bleaching, not prior heat exposure, increases heat tolerance of reef corals. Glob Change Biol. 2015;21:236-49. 
15. Enríquez S, Méndez ER, Iglesias-Prieto R. Multiple scattering on coral skeletons enhances light absorption by symbiotic algae. Limnol Oceanogr. 2005;50:1025-32.

16. Kühl M, Cohen Y, Dalsgaard T, Jorgensen BB, Revsbech NP. Microenvironment and photosynthesis of zooxanthellae in scleractinian corals studied with microsensors for $\mathrm{O}_{2}, \mathrm{pH}$ and Light. Mar Ecol Prog Ser. 1995;117:159-72

17. Terán E, Méndez ER, Enríquez S, Iglesias-Prieto R. Multiple light scattering and absorption in reef-building corals. Appl Optics. 2010;49:5032-42.

18. Marcelino LA, Westneat MW, Stoyneva V, Henss J, Rogers JD, Radosevich $A$, et al. Modulation of light-enhancement to symbiotic algae by light-scattering in corals and evolutionary trends in bleaching. PLoS One. 2013;8:e61492.

19. Wangpraseurt D, Larkum AWD, Franklin J, Szabo M, Ralph PJ, Kühl M. Lateral light transfer ensures efficient resource distribution in symbiontbearing corals. J Exp Biol. 2014;217:489-98.

20. Ban SS, Graham NAJ, Connolly SR. Evidence for multiple stressor interactions and effects on coral reefs. Glob Change Biol. 2014;20:681-97.

21. Jones RJ, Hoegh-Guldberg O. Diurnal changes in the photochemical efficiency of the symbiotic dinoflagellates (Dinophyceae) of corals: photoprotection, photoinactivation and the relationship to coral bleaching. Plant Cell Environ. 2001;24:89-99.

22. Warner ME, Fitt WK, Schmidt GW. Damage to photosystem II in symbiotic dinoflagellates: a determinant of coral bleaching. P Natl Acad Sci USA. 1999;96:8007-12.

23. Iglesias-Prieto R, Matta JL, Robins WA, Trench RK. Photosynthetic response to elevated temperature in the symbiotic dinoflagellate Symbiodinium microadriaticum in culture. P Natl Acad Sci USA. 1992;89:10302-5.

24. Bhagooli R, Hidaka M. Comparison of stress susceptibility of in hospite and isolated zooxanthellae among five coral species. J Exp Mar Biol Ecol. 2003;291:181-97.

25. Bhagooli R, Hidaka M. Photoinhibition, bleaching susceptibility and mortality in two scleractinian corals, Platygyra ryukyuensis and Stylophora pistillata, in response to thermal and light stresses. Comp Biochem Phys A. 2004;137:547-55.

26. Mumby PJ, Chisholm JRM, Edwards AJ, Andrefouet S, Jaubert J. Cloudy weather may have saved Society Island reef corals during the 1998 ENSO event. Mar Ecol Prog Ser. 2001;222:209-16.

27. Stambler N, Dubinsky Z. Corals as light collectors: an integrating sphere approach. Coral Reefs. 2005;24:1-9.

28. Wangpraseurt D, Larkum AWD, Ralph PJ, Kühl M. Light gradients and optical microniches in coral tissues. Front Microbiol. 2012;3:316.

29. Rodríguez-Roman A, Hernández-Pech X, Thomé PE, Enríquez S, IglesiasPrieto R. Photosynthesis and light utilization in the Caribbean coral Montastraea faveolata recovering from a bleaching event. Limnol Oceanogr. 2006;51:2702-10.

30. Kaniewska P, Magnusson SH, Anthony KRN, Reef R, Kühl M, Hoegh-Guldberg $\mathrm{O}$. Importance of macro-versus microstructure in modulating light levels inside coral colonies. J Phycol. 2011;47:846-60.

31. Anthony KRN, Hoogenboom MO, Connolly SR. Adaptive variation in coral geometry and the optimization of internal colony light climates. Funct Ecol. 2005;19:17-26.

32. Wangpraseurt D, Polerecky L, Larkum AWD, Ralph PJ, Nielsen DA, Pernice M, Kühl M. The in situ light microenvironment of corals. Limnol Oceanogr. 2014;59:917-26.

33. Salih A, Larkum A, Cox G, Kühl M, Hoegh-Guldberg O. Fluorescent pigments in corals are photoprotective. Nature. 2000;408:850-3.

34. Stolarski J. Three-dimensional micro- and nanostructural characteristics of the scleractinian coral skeleton: a biocalcification proxy. Acta Palaeontol Pol. 2003;48:497-530.

35. Cuif JP, Dauphin Y. The environment recording unit in coral skeletons-a synthesis of structural and chemical evidences for a biochemically driven, stepping-growth process in fibres. Biogeosciences. 2005;2:61-73.

36. Enríquez S, Mendez E, Hoegh-Guldberg O, Iglesias-Prieto R. Morphological dependence of the variation in the light amplification capacity of coral skeleton. In: 11th International Coral Reef Symposium; Ft. Lauderdale: 2008. p. 5-18.

37. Rogers JD, Çapoğlu IR, Backman V. Nonscalar elastic light scattering from continuous random media in the Born approximation. Opt Lett. 2009;34:1891-3.
38. Ralph PJ, Larkum AWD, Kühl M. Photobiology of endolithic microorganisms in living coral skeletons: 1. Pigmentation, spectral reflectance and variable chlorophyll fluorescence analysis of endoliths in the massive corals Cyphastrea serailia, Porites lutea and Goniastrea australensis. Mar Biol. 2007;152:395-404.

39. Krause GH, Weis E. Chlorophyll fluorescence and photosynthesis. The basics. Ann Rev Plant Phys. 1991;42:313-49.

40. Iglesias-Prieto R, Beltrán VH, LaJeunesse TC, Reyes-Bonilla H, Thomé PE. Different algal symbionts explain the vertical distribution of dominant reef corals in the eastern Pacific. P Roy Soc B Biol Sci. 2004;271:1757-63.

41. Warner ME, LaJeunesse TC, Robison JD, Thur RM. The ecological distribution and comparative photobiology of symbiotic dinoflagellates from reef corals in Belize: potential implications for coral bleaching. Limnol Oceanogr. 2006;51:1887-97.

42. Kramer DM, Johnson G, Kiirats O, Edwards GE. New fluorescence parameters for the determination of QA redox state and excitation energy fluxes. Photosynth Res. 2004;79:209-18.

43. Robison JD, Warner ME. Differential impacts of photoacclimation and thermal stress on the photobiology of four different phylotypes of Symbiodinium (Pyrrhophyta). J Phycol. 2006;42:568-79.

44. Hill R, Larkum AWD, Prasil O, Kramer DM, Szabo M, Kumar V, Ralph PJ. Light-induced dissociation of antenna complexes in the symbionts of scleractinian corals correlates with sensitivity to coral bleaching. Coral Reefs. 2012;31:963-75.

45. Warner ME, Lesser MP, Ralph PJ. Chlorophyll fluorescence in reef building corals. In: Suggett DJ, Prášil O, Borowitzka MA, editors. Chlorophyll a fluorescence in aquatic sciences: methods and application, vol 4. New York: Springer; 2010. p. 209-22.

46. Ragni M, Airs RL, Hennige SJ, Suggett DJ, Warner ME, Geider RJ. PSII photoinhibition and photorepair in Symbiodinium (Pyrrhophyta) differs between thermally tolerant and sensitive phylotypes. Mar Ecol Prog Ser. 2010;406:57-70.

47. Warner ME, Fitt WK, Schmidt GW. The effects of elevated temperature on the photosynthetic efficiency of zooxanthellae in hospite from four different species of reef coral: a novel approach. Plant Cell Environ. 1996;19:291-9.

48. Hill R, Frankart C, Ralph PJ. Impact of bleaching conditions on the components of non-photochemical quenching in the zooxanthellae of a coral. J Exp Mar Biol Ecol. 2005;322:83-92.

49. Jimenez IM, Larkum AWD, Ralph PJ, Kühl M. Thermal effects of tissue optics in symbiont-bearing reef-building corals. Limnol Oceanogr. 2012;57:1816-25.

50. Lesser MP. Coral bleaching: causes and mechanisms. In: Coral reefs: an ecosystem in transition. 2011. p. 405-19.

51. Dove S. Scleractinian corals with photoprotective host pigments are hypersensitive to thermal bleaching. Mar Ecol Prog Ser. 2004;272:99-116.

52. Brown BE, Downs CA, Dunne RP, Gibb SW. Preliminary evidence for tissue retraction as a factor in photoprotection of corals incapable of xanthophyll cycling. J Exp Mar Biol Ecol. 2002;277:129-44.

53. Middlebrook R, Anthony KRN, Hoegh-Guldberg O, Dove S. Heating rate and symbiont productivity are key factors determining thermal stress in the reef-building coral Acropora formosa. J Exp Biol. 2010;213:1026-34.

54. Berkelmans R, van Oppen MJH. The role of zooxanthellae in the thermal tolerance of corals: a'nugget of hope'for coral reefs in an era of climate change. P Roy Soc B Biol Sci. 2006;273:2305-12.

55. Cunning R, Baker AC. Excess algal symbionts increase the susceptibility of reef corals to bleaching. Nature Climate Change. 2013;3:259-62.

56. Hume B, D'Angelo C, Burt J, Baker AC, Riegl B, Wiedenmann J. Corals from the Persian/Arabian Gulf as models for thermotolerant reef-builders: prevalence of clade C3 Symbiodinium, host fluorescence and ex situ temperature tolerance. Mar Pollut Bull. 2013;72:313-22.

57. Fitt WK, Gates RD, Hoegh-Guldberg O, Bythell JC, Jatkar A, Grottoli AG, et al. Response of two species of Indo-Pacific corals, Porites cylindrica and Stylophora pistillata, to short-term thermal stress: the host does matter in determining the tolerance of corals to bleaching. J Exp Mar Biol Ecol. 2009;373:102-10.

58. Howells EJ, Beltran VH, Larsen NW, Bay LK, Willis BL, van Oppen MJH. Coral thermal tolerance shaped by local adaptation of photosymbionts. Nature Climate Change. 2012;2:116-20. 
59. Lesser MP, Stat M, Gates RD. The endosymbiotic dinoflagellates (Symbiodinium sp.) of corals are parasites and mutualists. Coral Reefs. 2013;32:603-11.

60. Doyle JJ, Doyle JL. A rapid DNA isolation procedure for small quantities of fresh leaf tissue. Phytochem Bull. 1987;19:11-5.

61. Veron JEN. Corals of the World, vol 1,2, and 3. Townsville: Australian Institute of Marine Science; 2000.

62. Kim YL, Liu Y, Turzhitsky VM, Roy HK, Wali RK, Backman V. Coherent backscattering spectroscopy. Opt Lett. 2004;29:1906-8.

63. Roy H, Turzhitsky V, Kim Y, Goldberg M, Watson P, Rogers J, et al. Association between rectal optical signatures and colonic neoplasia: potential applications for screening. Cancer Res. 2009;69:4476-83.

64. Turzhitsky V, Rogers JD, Mutyal NN, Roy HK, Backman V. Characterization of light transport in scattering media at subdiffusion length scales with low-coherence enhanced backscattering. IEEE J Sel Top Quant. 2010;16:619-26

65. Radosevich AJ, Mutyal NN, Turzhitsky V, Rogers JD, Yi J, Taflove A, Backman V. Measurement of the spatial backscattering impulse-response at short length scales with polarized enhanced backscattering. Opt Lett. 2011;36:4737-9

66. Radosevich AJ, Eshein A, Nguyen T-Q, Backman V. Subdiffusion reflectance spectroscopy to measure tissue ultrastructure and microvasculature: model and inverse algorithm. J Biolmed Opt. 2015;20:97002.

67. Hoegh-Guldberg O, Jones RJ. Photoinhibition and photoprotection in symbiotic dinoflagellates from reef-building corals. Mar Ecol Prog Ser. 1999;183:73-86.

68. Rogers JE, Marcovich D. A simple method for the extraction and quantification of photopigments from Symbiodinium spp. J Exp Mar Biol Ecol. 2007;353:191-7

69. Veal CJ, Carmi M, Fine M, Hoegh-Guldberg O. Increasing the accuracy of surface area estimation using single wax dipping of coral fragments. Coral Reefs. 2010;29:893-7.

70. West BT, Welch KB, Galecki AT. Linear mixed models: a practical guide using statistical software. Abingdon-on-Thames: Taylor \& Francis; 2006.

71. Kaandorp JA, Sloot PMA, Merks RMH, Bak RPM, Vermeij MJA, Maier C. Morphogenesis of the branching reef coral Madracis mirabilis. P Roy Soc B Biol Sci. 2005;272:127-33.
72. Ulstrup KE, Ralph PJ, Larkum AWD, Kühl M. Intra-colonial variability in light acclimation of zooxanthellae in coral tissues of Pocillopora damicornis. Mar Biol. 2006;149:1325-35.

73. Jimenez IM, Kühl M, Larkum AWD, Ralph PJ. Effects of flow and colony morphology on the thermal boundary layer of corals. J Roy Soc Interface. 2011;8:1785-95.

74. Cohen AL, Smith SR, McCartney MS, van Etten J. How brain corals record climate: an integration of skeletal structure, growth and chemistry of Diploria labyrinthiformis from Bermuda. Mar Ecol Prog Ser. 2004;271:147-58.

75. Fisher PL, Malme MK, Dove S. The effect of temperature stress on coralSymbiodinium associations containing distinct symbiont types. Coral Reefs. 2012;31:473-85.

76. Sampayo EM, Ridgway T, Bongaerts P, Hoegh-Guldberg O. Bleaching susceptibility and mortality of corals are determined by fine-scale differences in symbiont type. P Natl Acad Sci USA. 2008;105:10444-9.

77. Wang JT, Meng PJ, Chen YY, Chen CA. Determination of the thermal tolerance of Symbiodinium using the activation energy for inhibiting photosystem II activity. Zool Stud. 2012;51:137-42.

78. LaJeunesse TC, Smith RT, Finney J, Oxenford H. Outbreak and persistence of opportunistic symbiotic dinoflagellates during the 2005 Caribbean mass coral 'bleaching' event. P Roy Soc B Biol Sci. 2009;276:4139-48.

79. Folmer O, Black M, Hoeh W, Lutz R, Vrijenhoek R. DNA primers for amplification of mitochondrial cytochrome c oxidase subunit I from diverse metazoan invertebrates. Mol Mar Biol Biotech. 1994;3:294-9.

80. Fukami H, Budd AF, Levitan DR, Jara J, Kersanach R, Knowlton N. Geographic differences in species boundaries among members of the Montastraea annularis complex based on molecular and morphological markers. Evolution. 2004;58:324-37.

81. MCFadden CS, Donahue R, Hadland BK, Weston R. A molecular phylogenetic analysis of reproductive trait evolution in the soft coral genus Alcyonium. Evolution. 2001;55:54-67.

82. Santos SR, Taylor DJ, Kinzie RA, Hidaka M, Sakai K. Coffroth MA (2002) Molecular phylogeny of symbiotic dinoflagellates inferred from partial chloroplast large subunit (23S)-rDNA sequences. Mol Phylogenet Evol. 2002;23:97-111.

\section{Submit your next manuscript to BioMed Central and we will help you at every step:}

- We accept pre-submission inquiries

- Our selector tool helps you to find the most relevant journal

- We provide round the clock customer support

- Convenient online submission

- Thorough peer review

- Inclusion in PubMed and all major indexing services

- Maximum visibility for your research

Submit your manuscript at www.biomedcentral.com/submit
( Biomed Central 